\title{
The Impact of the Coronavirus (Sars-Cov-2) Lockdown on Crime in New York and London, March-June 2020: A Comparative Study
}

\author{
Anna Murdoch ${ }^{1}$, Caroline Byczynski ${ }^{2}$ \\ ${ }^{I}$ Independent scholar, Warsaw, Poland \\ ${ }^{2}$ International Career Institute (ICI), Sydney, Australia \\ *Correspondence: Anna Murdoch, Email: 2danae2@gmail.com
}

\begin{abstract}
The objective of this paper is to assess the relationship between The Spring 2020 COVID-19 Lockdown and the levels of crime in New York City (NYC) and London. Our proposition, derived from the Routine Activity Theory (RAT), the 'breaches' theory and input from the 2020 research on lockdown and crime, hypothesised that lockdown measures would lead to reductions in crime. The crime categories selected for this study were: homicide, rape, robbery, violence against a person, burglary, theft and vehicle theft. T-test, F-test and the Ordinary Least Squares (OLS) regression calculations were used to test the hypotheses. The four-month lockdown period in 2020 produced a $15 \%$ and $31 \%$ crime reduction in NYC and London, respectively. In the case of London, the overall results indicate that changes in routine human activities were indeed largely correlated with the reduction in crime. However, crime patterns in NYC in spring 2020 turned out to be inconsistent. A comparison of crime patterns under lockdown proved dissimilarity between NYC and London. The two-city comparison indicates that crime change related to lockdown may vary across crime types, places, and timespans or may have a detrimental effect on crime levels. The study may be considered suitable for replication and elaboration, particularly in view of the extended longevity of lockdown measures.
\end{abstract}

Keywords: COVID-19, Lockdown measures, New York City, London, Crime patterns, Crime reduction, Crime pattern dissimilarity

\section{ARTICLE INFORMATION}

Author(s): Anna Murdoch, Caroline Byczynski

Received: 28 Feb, 2021; Accepted: 06 Apr, 2021; Published: 10 May 2021;

e-ISSN: 2347-4696;

Paper Id: BMN-IJBMR-2021-29;

Citation: doi.org/10.37391/IJBMR.090204

Webpage-link:

https://ijbmr.forexjournal.co.in/archive/volume-9/ijbmr-090204.html

\section{INTRODUCTION}

The COVID-19 infection, caused by the SARS-CoV-2 virus, was first observed and made public in the Chinese province of Wuhan in 2019. Following the World Health Organisation (WHO) announcement on 11 March 2020, regarding the pandemic nature of the infection, most countries reacted correspondingly and introduced varying degrees of lockdown measures (in short: lockdown), alternatively called containment policies. Lockdown was introduced in the United Kingdom (UK) on 23 March 2020, following the Coronavirus $\mathrm{Act}^{1}$, later amended, based upon the guidance of Public Health

1 The Coronavirus Act was based upon the guidance of Public Health Services, however it did allow provisions for individual judgement. Due to the flexible nature and interpretation of the act, it was up to chief constables to establish how these provisions would be applied in the local area. A positive coronavirus test allowed for police officers to intervene so long as the positive test was announced. The way in which cases were handled was up to police forces but the Public Health Service could be called upon for advice if needed [1]
Services, which gave the UK government the power to limit or suspend public gatherings, to quarantine those individuals who were infected or affected, and to intervene in critical sectors in order to contain the spread of the disease, thus limiting the freedom of movement, mobility, as well as the right to exercise, work, study and entertain [2, 3].

The phased lifting of the measures started in the UK on 13 May 2020 and continued in three stages, with the most pronounced 'back to normal' activities, such as encouraging those who could not work from home to return to the workplace, and the re-opening of sport, education and leisure facilities from 15 June 2020, staggered across the four nations [4].

Lockdown measures, such as stay-at-home orders, curfews, shutdowns and other limitations were similarly introduced in the United States (US) after the WHO announcement. In the US, due to the federal nature of the country, each state governor declared the lockdown at varying times, following President Donald Trump's recommendation, announced on 16 March 2020. New York State, together with the states of New Jersey and Connecticut, introduced lockdown on 16 March 2020. The lockdown started to be lifted in New York State on 15 May 2020 and 8 June 2020 in New York City itself. In summary, NYC preceded London in the lockdown introduction by one week; however, London preceded NYC in lockdown lifting by four weeks despite imposing the lockdown later.

This study explores the relationship between the COVID-19 lockdown measures and crime in New York City and London. 
The analysis examines changes in patterns of the following crime categories, in NYC: murder, rape, robbery, assault, burglary, grand larceny, grand larceny auto, and in London: homicide, rape, robbery, violence against a person, burglary, theft, vehicle theft (theft of or from a vehicle), resulting from the COVID-19 lockdown measures and associated changes to routine activities. The crime terminology differences (US vs. UK) have been applied consistently throughout the paper.

The fundamental presumption for the study stems from the observance that change in life routines alters expected crime levels. This assumption was drawn from the theoretical contribution of environmental criminologists [5] and is rooted in the Routine Activity Theory (RAT) [5] as well as the Crime Pattern Theory (CPT) [7, 8]. According to environmental criminology, crime is driven by opportunities. A crime opportunity forms when a motivated offender comes into contact with a suitable target in the absence of capable guardians. The early spring 2020 lockdown measures significantly disrupted the supply of such opportunities to the extent that it is expected that crime levels will have changed correspondingly, for some crime categories probably more than for others.

A further foundation for this study was drawn from the rapidly growing body of work on the crime effects of the pandemic [911], as discussed in more detail in the Literature Review section of this paper.

This study also exploited the observation that the introduction of lockdown could be viewed as a profound change in everyday patterns of behaviour (not only crime-related) called a 'breach' [12], which results from a technological or social development. Some other scholars, for example Stickle and Felson [13] described the lockdown as a type of 'natural social experiment'. This profound change, widely reported in the current scholarly and popular body of literature, across genres, resulted in numerous repercussions in people's lives, in areas such as education, work and leisure and, last but not least, produced changes in crime patterns. For instance, it was found that two particular measures of lockdown, that is, social distancing and stay-home orders, limited the pool of otherwise common opportunities for theft as well as burglary [14] although not as consistently as had been expected.

Following the assumptions drawn from the RAT and CPT foundations, the 'breaches' proposition as well as the conclusions reported from the contemporaneous observation of the lockdown, this study focused on the changes to crime volume and statistical characteristics in the two, already listed, geographical locations, New York City and London. The locations were a convenience sample, while their respective population size - NYC with 8.4 million and London with 8.89 million - made the comparison feasible. The cities constitute hubs for the US and the UK, respectively and have arrived at comparable levels of civilisational, economic and social development. Under normal circumstances, both NYC and London had experienced a barrage of constant, persistent and rich criminal activity. In order to enrich the scope of the study a comparative approach was chosen, both in the chronological (2019 vs. 2020) and crime categories.

The convenience-dictated choice of locations, even if rationalised by the multiple similarities, also in crime data, involved an important methodological standardisation procedure, namely that referring to the samples. The samples, as utilised in the paper, that is the number of crime incidents committed in the NYC and London area respectively, were counted, processed and presented in a different manner by the respective police authorities, also in the period under question. That is to say that the respective police records were not equal from the methodological point of view. The London's Metropolitan Police (MET) data presentation was substantially more detailed and comprehensive, while the NYC data was in comparison - condensed and less detailed. In view of the data differences between the samples, the comparative descriptive analysis in the paper relied predominantly on the relative changes in crime trends, while the means and variance equality tests were applied in the relevant inferential statistics analysis.

The data was drawn from open sources, namely: the New York Police Department (NYPD) records ${ }^{2}$, and the Metropolitan Police resources ${ }^{3}$. The analysis covered March through June 2019 and March through June 2020.

The first eight hypotheses, grounded in the RAT literature, sought to establish the relationship between lockdown and crime, in a comparative manner: both year-on-year and city-tocity. The further seven hypotheses, based on the same crime categories, looked to identify a possible relationship between the number of the Covid-19 cases in both cities, reported daily and aggregated accordingly, treated as a proxy for the independent variable (i.e., lockdown), and crime pattern changes.

The analysis of the trends in the selected crime types in both cities led to the conclusion that there are numerous patterns reflecting the crime evolution in the first four-month lockdown period in 2020: a decrease, increase, initial decrease and then a rise, or fluctuations in the number of crime incidents. These initial observations suggest that the lockdown truly led to the preliminary (albeit short-term) drop in the number of incidents in some selected crime categories. This conclusion was therefore recognised to partly support the RAT, confirming the rule that crime reduction indeed results from both impeded crime opportunities as well as an increased degree of guardianship, particularly in London, where six out of the seven initial Hypotheses were validated. However, the growth/decline trends as well as the dispersion and mean characteristics of the crime distributions proved trend dissimilarity in both locations. Additionally, the supposition which stated that the dispersion of crime would be larger in

2 https://www1.nyc.gov/site/nypd/stats/crimestatistics/citywide-crime-stats.page

3 https://www.met.police.uk/sd/stats-and-data/met/crime-datadashboard/ 
2019 than in 2020 (Hypothesis 8), was only validated for the total aggregated number of crime incidents in NYC. In conclusion, the overall results of the analysis point to mixed conclusions, similarly to the findings of several contemporaneous research studies, namely that the initial drop in the selected crime categories did not prove to be sustainable. The findings from the analysis follow the observation of Stickle and Felton [13] that crime rates "have indeed changed, but unequally across different categories, types, places, and timeframes".

Therefore, the results of this study should be treated with caution. In consequence, the recommendations from the study findings focus primarily on directions for further studies. Policy makers are recommended to consider and estimate the costs of maintaining the lockdown, especially in view of the temporary character of the cost reducing effect on crime as well as certain detrimental repercussions as regards crime trends.

Some editorial conventions have been applied in this paper, in order to avoid unnecessary repetitions. The data and findings are first presented for NYC and then London throughout the paper. Some preliminary statistical test results were moved to the Appendix. Finally, the sources of data in the case of tables and figures were listed in the relevant footnotes and subsequently referred to in the text.

\section{LITERATURE REVIEW}

\subsection{Opportunity Theories of Crime}

Opportunity theories of crime, also associated with environmental criminology [15] investigate the physical and social characteristics of crime, circumstances which bring the offender and the target together, cognitive processes leading to the selection of the crime type and crime location, the influence of laws and procedures onto crime sites as well as the spatial distribution of crime in rural, urban and suburban settings [5]. One of the major examples of an opportunity theory of crime is The Routine Activity Theory.

Routine Activity Theory emerged amongst the numerous efforts undertaken in crime studies which served to explain the rise in crime in the United States after the Second World War [16]. For example, following World War II, the US saw a rise in criminal activity, which stood in contrast to the traditional theories that regarded poverty as the key driver of crime. While many scholars had tried to explain the phenomenon, it was Cohen \& Felson [6] who demonstrated that crime patterns can be seen to increase in highly populated areas, in which the likelihood of victims and offenders meeting increases due to the law of large numbers. They determined that criminal activity relies on a few key factors converging in time and space: the offender, the target, and the lack of protection of the target. Routine Activity Approach (RAA) circumscribes that such a convergence of factors is not random and erratic but constitutes an epiphenomenon that occurs alongside the patterns of daily life.
Cohen and Felson [6] noted that repeated, mundane and regularly and/or cyclically maintained spatial and temporal patterns give rise to opportunities through which potential offenders and targets can come into contact or interaction, and which may transform into a criminal incident. Since 1979 the RAT has been refined by numerous authors who contributed to the theory [17] and created a model with six key elements: targets/victims, guardians, places, managers, offenders and handlers. The six elements proposed by the theory were presented as an inner/outer triangle model by Eck [18]. The inner triangle includes the three conditions which may co-exist for the crime to occur: the offender, the victim and the place, as presented by Cohen and Felson [6] and other proponents of the RAT. The outer triangle represents the three protective elements, which could prevent or thwart the crime: a handler (a crime prevention agent), a guardian (e.g., a parent) and a (place) manager (e.g., a store guard on duty). The triangle model is presented in Figure 1.

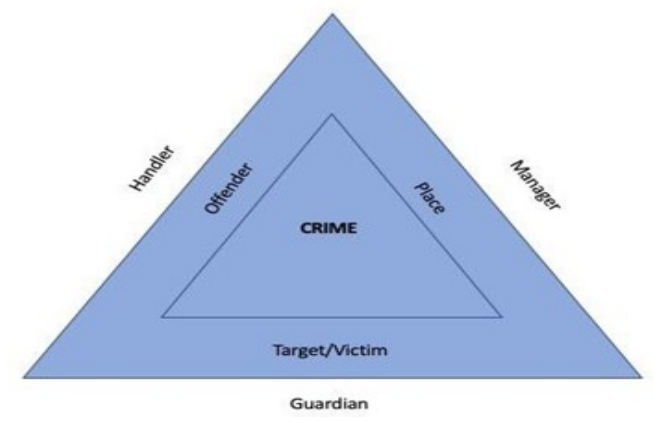

Figure 1: The inner and outer crime model (based on Eck, 2003)

Various scholars pointed out that changes to patterns in every day routines are not the only catalyst which may spur criminal activity. For example, Tilley and Sidebottom [16], elaborating on Cohen and Felson [6], listed several examples of routine activities, brought about by sweeping social changes, which facilitated the rise of crime opportunities, such as the incorporation of women into the labour force post-war in the 20th century, which lead to reduced guardianship of homes and thus created increased opportunities for burglary. Tilley and Sidebottom [16] also pointed out the role of technological progress, such as the invention and proliferation of portable electronic devices, for example cameras, iPods, iPads and mobile phones. Another trend was lifestyle changes, such as the boom in travel and holiday industries, which gave rise to notorious theft incidents and notoriously infamous tourist locations prone to pick-pocketing. On the other hand, the presence or absence of guardians may detain the potential offender from a harmful or offensive action [16] for example, in situations involving children.

The RAT was recently subject to testing via a real-life experiment, defined by one set of authors as "a naturally occurring, quasi-randomised control experiment" [13], while the lockdown measures were introduced worldwide to stop the spread of COVID-19. In this paper, it is anticipated that the 
lockdown affected, to be more precise: reduced, the number of criminal incidents in the period from March through June 2020. Moreover, an inference was drawn from the proposition, illustrated by the triangle model regarding the (capable) guardianship. It was hypothesised that an increased level of guardianship within households, caused by the stay-home orders, may have reduced the number of burglaries, possibly also car theft incidents, in the corresponding period.

The process of conceptualisation deployed in this paper was further supported by the literature on large scale disruptions to daily life, namely: war, economic crises, natural disasters and large sports events as well as the theory of 'breaches' [12].

\subsection{The Impact of a Large-scale Disruption of} Day-to-day Life onto Crime: War, Economic Crisis. Natural Disasters, 'Breaches' and Changes Caused by Technological Development

Several post-RAT studies have explored the proposition that a large-scale disruption of day-to-day life could have an impact on crime patterns. The disruptions in question included those experienced after large scale natural disasters [19], in the aftermath of a war as well as during a cyclical or spontaneous severe economic crisis [20, 21]. Some other disruptions caused by or during major sporting events contributed to the malfunction of traffic and public transport [22-24]. Ashby [9] identified two major differences between a pandemic and sudden natural disaster, pointing out that a pandemic has a slow onset, and it leaves the physical environment fundamentally undisturbed.

This latter body of literature, although it largely acknowledges the RAT fundamentals, differs from the RAT in the sense that it does not focus exclusively on daily routine alterations caused merely by the change in routine activities but locates the crime pattern changes within the context of multivariable disruptions and/or breakdowns in economic, social or even

\begin{tabular}{|l|l|l|l|}
\hline Author(s), 2020 & Data sets and time & Methodology & Key findings \\
\hline Ashby [9] & $\begin{array}{l}\text { 15 US cities, 2016-2020 } \\
\text { and January to 23 March, } \\
2020\end{array}$ & $\begin{array}{l}\text { Seasonal auto- regressive } \\
\text { integrated moving average } \\
\text { (SARIMA) models of crime in } \\
\text { previous years were used to } \\
\text { forecast the expected frequency } \\
\text { of crime in 2020 in the absence } \\
\text { of the pandemic. Forecasts from } \\
\text { the models and a comparative } \\
\text { analysis }\end{array}$ & $\begin{array}{l}\text { There were no significant changes in the } \\
\text { frequency of serious assaults in public or } \\
\text { (contrary to the concerns of policy makers) } \\
\text { any change to the frequency of serious } \\
\text { assaults in residences. In some cities (Austin, } \\
\text { Los Angeles, Memphis and San Francisco), } \\
\text { there were reductions in residential burglary } \\
\text { but little change in non- residential burglary }\end{array}$ \\
\hline $\begin{array}{l}\text { Brantingham, et } \\
\text { al. [25] }\end{array}$ & $\begin{array}{l}\text { Los Angeles, 20 January - } \\
\text { 13 April 2020 and to July }\end{array}$ & $\begin{array}{l}\text { Difference-indifferences } \\
\text { approach, geospatial changes in } \\
\text { hotspots, ethnographic evidence } \\
\text { from South and East LA }\end{array}$ & $\begin{array}{l}\text { No statistical change in hot spots; no impact } \\
\text { of social unrest; no visible impact on gang- } \\
\text { related crime; initial reduction followed by a } \\
\text { quick return to business as usual' }\end{array}$ \\
\hline
\end{tabular}

ontological foundations in human life. Prior to the "pandemic scholarly literature', in 2006, there emerged a proposition stated by Killias [12], which defines several types of new opportunities ('breaches') for crime, resulting from the changes in everyday patterns of behaviour, which themselves are caused by technological or social development. Other types of breaches, listed by Killias [12], irrespective of their lifespan, result from sweeping, consequence-laden political decisions, such as the end of the cold war, followed by profound systemic changes in post-communist countries or the 1991 re-unification of Germany. Furthermore, Killias [12] argues that certain 'breaches' so exceed the status quo that they may give rise to novel criminal activities not yet envisaged by the lawmakers [12]. Stickle and Felson [13], on the other hand, claim that the recent, lockdown induced changes in crime ("the most salient aspect of the steep fall in crime") are the consequence of the politically empowered legal stay-at-home orders. However, the growing body of the most recent scholarly literature on the effects of a series of lockdowns may yet have to come out with more consistent conclusions. Presently, those conclusions cannot be perceived as unequivocal.

\subsection{Initial Evidence of the Covid-19 Pandemic Repercussions in the Volume and Intensity of Criminal Cases: Contemporary Studies}

The theoretical foundations in this study were complemented and completed by the contribution of the plethora of relevant contemporaneous papers published during the initial stages of the pandemic. As already pointed out, the relevant authors also grounded their research in the RAT and examined the effect of lockdown on the levels and patterns of crime in various locations, primarily urban US environments, sometimes in a comparative fashion. Table 1 summarises some of these studies. 


\begin{tabular}{|c|c|c|c|}
\hline $\begin{array}{l}\text { Campedelli, } \\
\text { Aziani, Favarin } \\
{[26]}\end{array}$ & $\begin{array}{l}\text { Los Angeles, } 1 \text { January } \\
2017 \text { to } 28 \text { March } 2020\end{array}$ & $\begin{array}{l}\text { Bayesian structural time- } \\
\text { series (BSTS) models }\end{array}$ & $\begin{array}{l}\text { Overall crime in Los Angeles found as } \\
\text { decreasing, as well as robbery, shoplifting, } \\
\text { theft and battery. No significant effect has } \\
\text { been found for stolen vehicle, burglary, } \\
\text { assault with deadly weapon, intimate partner } \\
\text { violence and homicide }\end{array}$ \\
\hline $\begin{array}{l}\text { Campedelli, } \\
\text { Aziani, Piquero } \\
{[10]}\end{array}$ & $\begin{array}{l}\text { Chicago ( } 77 \\
\text { communities) }\end{array}$ & $\begin{array}{l}\text { Bayesian Time Series models, } \\
\text { Firth Logistic Regression }\end{array}$ & $\begin{array}{l}\text { The results show that burglaries dropped } \\
\text { significantly in } 10(12.98 \%) \text { communities, } \\
\text { with } 2(2.59 \%) \text { proving a statistical } \\
\text { increase }(+219 \% \text { and }+168 \% \text {, respectively). } \\
\text { Assaults dropped in } 18(23.37 \%) \\
\text { communities, while one experienced an } \\
\text { increase of }+115 \% \text {. Drug related crimes } \\
\text { went down in } 35 \text { locations ( } 45.54 \%) \text {. Most } \\
\text { of those communities had been } \\
\text { characterised by high levels of crime before } \\
\text { the pandemic [27]. No community } \\
\text { experienced a rise in narcotics- related } \\
\text { crimes. The number of robberies went down } \\
\text { significantly in } 10 \text { ( } 12.98 \%) \text { communities, } \\
\text { with one community recording a significant } \\
\text { increase }\end{array}$ \\
\hline $\begin{array}{l}\text { Halford, et al. } \\
\text { [28] }\end{array}$ & $\begin{array}{l}\text { Recorded crime data from } \\
\text { a UK police service } \\
\text { covering over } 5,000 \\
\text { square kilometres ( } 2000 \\
\text { square miles) with a } \\
\text { population of around } 1.5 \\
\text { million (2020) }\end{array}$ & $\begin{array}{l}\text { Comparison of means; } \\
\text { calculation of the mobility } \\
\text { elasticity of crime for four } \\
\text { crime types, shoplifting, } \\
\text { burglary, assault and motor } \\
\text { vehicle theft }\end{array}$ & $\begin{array}{l}\text { One week after lockdown, all recorded } \\
\text { crime had declined } 41 \% \text { with variation by } \\
\text { type: shoplifting }(-62 \%) \text {, theft }(-52 \%) \text {, } \\
\text { domestic abuse }(-45 \%) \text {, theft from vehicle } \\
(-43 \%) \text {, assault }(-36 \%) \text {, burglary: dwelling } \\
(-25 \%) \text { and burglary non- dwelling }(-25 \%) \text {, } \\
\text { compared to their expected rates. } \\
\text { Shoplifting is elastic to reduced grocery } \\
\text { sector mobility (MEC }>2) \text {, burglary } \\
\text { dwelling is elastic to increases in residential } \\
\text { area mobility }(-1) \text {, while assault and theft } \\
\text { from a motor vehicle are inelastic but still } \\
\text { responsive to reduced movement under } \\
\text { lockdown }(0.48 \text { and } 0.69 \text { respectively) }\end{array}$ \\
\hline $\begin{array}{l}\text { Mohler, et al. } \\
{[14]}\end{array}$ & $\begin{array}{l}\text { Daily counts of calls for } \\
\text { police service in Los } \\
\text { Angeles, January 2, } 2020 \\
\text { to April 18, 2020 and } \\
\text { Indianapolis, Indiana } \\
\text { from 2 January } 2020 \\
\text { through 21 April } 2020\end{array}$ & $\begin{array}{l}\text { Differences in means from a } \\
\text { baseline period, a regression } \\
\text { using daily Google residential } \\
\text { mobility }\end{array}$ & $\begin{array}{l}\text { Burglary and robbery were significantly } \\
\text { lower in Los Angeles, but only marginally } \\
\text { lower in Indianapolis; assault/battery calls } \\
\text { were statistically unchanged in both } \\
\text { locations. The overall effect was notably } \\
\text { less than might be expected given the scale } \\
\text { of the disruption to social and economic life }\end{array}$ \\
\hline $\begin{array}{l}\text { Pietrawska, et } \\
\text { al. [29] }\end{array}$ & $\begin{array}{l}\text { Los Angeles in the first } \\
\text { three weeks of lockdown, } \\
\text { A Safe City Crime data }\end{array}$ & Trend analysis & $\begin{array}{l}\text { A } 64 \% \text { increase in retail burglary, while } \\
\text { city-wide burglary rates went down by } 10 \%\end{array}$ \\
\hline $\begin{array}{l}\text { Pietrawska, et } \\
\text { al. [30] }\end{array}$ & $\begin{array}{l}\text { Los Angeles and Chicago } \\
\text { in the first three weeks of } \\
\text { lockdown; data from the } \\
\text { respective police } \\
\text { departments }\end{array}$ & Trend analysis and comparison & $\begin{array}{l}\text { A } 74 \% \text { reduction of crime in restaurants, } \\
\text { while city-wide crime declined } 35 \%\end{array}$ \\
\hline
\end{tabular}




\begin{tabular}{|l|l|l|l|}
\hline $\begin{array}{l}\text { Pietrawska, et } \\
\text { al. [31] }\end{array}$ & $\begin{array}{l}\text { Six weeks beginning 1 } \\
\text { March (2 March for New } \\
\text { York); Chicago, Los } \\
\text { Angeles, New York City, } \\
\text { Seattle; } \\
\text { datacityofchicago.org; } \\
\text { datalacity.org; } \\
\text { compstat.nypdonline.org; } \\
\text { data.seattle.gov }\end{array}$ & Trend analysis and comparison & $\begin{array}{l}\text { Homicide, rape, robbery, and aggravated } \\
\text { assault: a drop off in crime after the } \\
\text { lockdown introduction, a gradual recovery } \\
\text { of trends }\end{array}$ \\
\hline $\begin{array}{l}\text { Piquero, et al. } \\
\text { [11] }\end{array}$ & $\begin{array}{l}\text { Dallas, Dallas Police } \\
\text { Department, 1 January } \\
\text { 2020 through 27 April } \\
\text { 2020 }\end{array}$ & $\begin{array}{l}\text { Daily count of domestic } \\
\text { violence incidents, descriptive } \\
\text { statistics, trend analysis, } \\
\text { Poisson regression models, } \\
\text { forecasting ARIMA models }\end{array}$ & $\begin{array}{l}\text { An increase in domestic violence in the first } \\
\text { two weeks of introducing stay home orders } \\
\text { (24 March 2020), no lasting increase or } \\
\text { sustained high levels of domestic violence }\end{array}$ \\
\hline
\end{tabular}

Table 1: The most recent (2020) contemporary research on the study of the lockdown and crime relationship, by authors in the alphabetical order.

The conclusions drawn from the analysis of the above findings are as follows: the first weeks of the lockdown produced a decrease in crime incidents in several of the locations under respective investigations, e.g., residential burglaries in Los Angeles, Memphis, San Francisco, Phoenix and Montgomery county [9], although not in Louisville or Boston. Similarly, Ashby's [9] empirical evidence demonstrated that incidents of serious assault in public declined in Austin, Los Angeles, and Louisville, but not in other US cities. Those findings were confirmed by the results conducted on the data from Chicago [9] and in the UK in the first week of the lockdown [28].

However, the results of the study published in the Campedelli, Aziani, Favarin [26] paper, conducted on the Los Angeles data, did not corroborate the supposition that burglary (as a crime category presumably affected by the increased guardianship due to lockdown) underwent reduction. On the contrary, Pietrawska [30] showed that burglaries in Los Angeles increased by $64 \%$ although she simultaneously demonstrated that city-wide burglary rates went down by $10 \%$. Another group of scholars, Mohler, et al. [14], who also drew on the Los Angeles data (the number of calls for police service), noted that the overall effect of social distancing and stay-home orders was notably less pronounced than might be expected, including the anticipated rise in domestic violence. Indeed, more calls for police service in relation to domestic disputes were observed, however, they were not accompanied by an increase in domestic violence. Similarly, Piquero, et al. [11] noted that domestic violence did not prove to be on the rise in a consistent manner. Most scholars listed here, who researched the lockdown and crime relationship and who derived their rationale from the RAT school of thought, showed that the initial empirical results of their studies supported the theory, even if those results may not have turned out to be sustainable and were not consistent within various categories, crime types, places, and timespans, as distinctly concluded by Stickle and Felson [13].

In view of the theoretical foundations and the majority of the findings reported in the most contemporary studies, the proposition in this paper was put forward that the lockdown (nicknamed later The Spring 2020 Lockdown) which, according to all contemporary scholars referenced here, unequivocally affected routine patterns of human activity and had a reducing effect on crime in most locations researched, should also be tested and compared in New York City and London. The crime categories under investigation, as elucidated in the introductory section, are in New York City: murder, rape, robbery, assault, burglary, grand larceny, grand larceny auto, and in London: homicide, rape, robbery, violence against a person, burglary, theft, vehicle theft (theft of or from a vehicle).

The hypotheses were formulated in the customary pairs of the null and alternative propositions. In the case of the first eight categories, the independent variable was the time, in this case in four discrete measures, corresponding to the number of months: March, April, May and June in 2019 and 2020; the dependent variable, plotted against the time measures, was the number of crime incidents in the respective months, in four values, corresponding to the months, in the seven selected categories. In the case of Hypothesis 8, the proposition was to find out whether or not the aggregate crime trajectory in both cities in the relevant period was similar.

There followed a set of hypotheses, derived from the rationale which attempted to quantify the lockdown indirectly, via a proxy variable, in view of the impossibility to quantify the measures themselves (i.e., a collection of orders, recommendations and limitations) in their aggregate in an unequivocal, unambiguously quantified manner. As a collective variable, 'lockdown' may be perceived as ambiguous, thus rendering any attempt of a straightforward modelling of the correlations between the containment policies and crime rates also dubious. Therefore, the assumption was put forward to replace 'lockdown' with a proxy variable. It was the number of COVID-19 cases in the respected cities in the corresponding period that became the proxy variable. As those assumptions were not directly inferred from the core body of the underlying literature, the analysis applied to test Hypotheses 9-15 may be perceived as a work-in-progress experiment in the recent outcrop of COVID-19 and lockdown related research. The major intention was to seek an additional 
source of rationalisation and support for the first seven, that is, the core hypotheses.

The primary objective of the lockdown measures was the containment and, if possible, eradication of the disease, while in the absence of a widespread and effective cure, at least initially, as well as a vaccine - it was deemed to be the most significant disease prevention policy. One of the by-products of the lockdown was the hypothesised reduction in crime incidents. Such reasoning is actually present in one of the conclusions made by Stickle and Felson [13].

In the case of Hypotheses 9-15, the intention is to try and establish a possible correlation between the independent (proxy) variable, that is the number of COVID-19 cases in both cities in the relevant period, and the dependent variable, that is the number of crime incidents in the same period. Although there were criticisms regarding both the counting methodology in the case of the people falling victim to the disease, and the daily versus monthly counts of the variables, our regression tests were conducted in spite of the limitations. Therefore, seven more pairs of the customary null and alternative pairs of hypotheses were formulated.

\section{HYPOTHESES}

Hypotheses grounded in the RAT and the inner and outer triangle of crime literature came first. In NYC and in London, respectively:

1.

H0: Murder (homicide) will not reduce when lockdown measures are in place

H1: Murder (homicide) will reduce when lockdown measures are in place

2.

H0: Rape will not reduce when lockdown measures are in place

H2: Rape will reduce when lockdown measures are in place

3.

H0: Robbery will not reduce when lockdown measures are in place

H3: Robbery will reduce when lockdown measures are in place

\section{4.}

H0: Assault (violence against a person) will not reduce when lockdown measures are in place

H4: Assault (violence against a person) will reduce when lockdown measures are in place

\section{5.}

H0: Burglary will not reduce when lockdown measures are in place

H5: Burglary will reduce when lockdown measures are in place

6.
H0: Grand larceny (theft) will not reduce when lockdown measures are in place

H6: Grand larceny (theft) will reduce when lockdown measures are in place

7.

H0: Grand larceny auto (vehicle theft) will not reduce when lockdown measures are in place

H7: Grand larceny auto (vehicle theft) will reduce when lockdown measures are in place

Based on the reasoning that New York City and London represent a similar environment for crime development, as explained in the Introduction, while both were subject to the same exogenous factor represented by the lockdown, Hypothesis 8 was put forward:

8.

H0: Changes in crime will be not consistent in New York City and in London

H8: Changes in crime will be consistent in New York City and in London

Based on the hypothesised correlation between the number of COVID-19 cases and the number of crime incidents, Hypotheses 9-15 were put forward.

In New York City and London, respectively:

9.

H0: Murder (homicide) will not be correlated with COVID-19

H9: Murder (homicide) will be correlated with COVID-19

10.

H0: Rape will not be correlated with COVID-19

H10: Rape will be correlated with COVID-19

11

H0: Robbery will not be correlated with COVID-19

H11: Robbery will be correlated with COVID-19

12.

H0: Assault (violence against a person) will not be correlated with COVID-19

H12: Assault (violence against a person) will be correlated with COVID-19

13.

H0: Burglary will not be correlated with COVID-19

H13: Burglary will be correlated with COVID-19

14.

H0: Grand larceny (theft) will not be correlated with COVID19

H14: Grand larceny (theft) will be correlated with COVID-19

15 .

H0: Grand larceny (car theft) will not be correlated with COVID-19

H15: Grand larceny auto (car theft) will be correlated with COVID-19 


\section{METHODOLOGY}

The data for the study was accessed from publicly available reports published by the NYPD 4 , and the Metropolitan Police ${ }^{5}$, for NYC and London respectively. The timespan for the analysis encompasses March through June 2020 as well as the corresponding period in 2019. The data was published monthly and used for the analysis accordingly. The data for the number of the COVID-19 cases in NYC and London was accessed from online. ${ }^{6} 7$ All data sets were accessed in the period March through June 2020 and processed during the months June - September 2020.

\subsection{Descriptive Statistics}

The raw data was organised and processed using STATA 12.0. Descriptive statistics were used to present the data in Tables 2 and 3 , respectively. These tables depict the nominal change in the crime incidents, as well as the relative change in the corresponding months of 2019 and 2020. The complete relative change between the number of crime incidents, in each category, for both cities, for the corresponding months in 2019 and 2020, is presented in Table 4.

Tables 2, 3 and 4 are accompanied by the corresponding figures 2-15, illustrating crime evolution in each crime category comparatively in 2019 and 2020 in each city. The crime trends are presented in the graphs as simplified $(\mathrm{N}=4)$ linear functions. The descriptive statistics were followed by inferential statistics tests.

\subsection{Inferential Statistics}

The analysis of the variables and relationships was conducted at the bi-variate level, also with the help of the statistical software STATA 12.0. Due to the fact that the sample sizes were unequal, preliminary tests were performed. Tests of equality of variances were used as a pre-test for a two-sample comparison of means (paired), and were followed by the tests for equal and unequal variance. Subsequently, when necessary, a two-sample comparison of means test (paired) with Welch's correction for unequal variances was applied. The final results are presented individually for each Hypothesis in Tables 5 and 6. Table 7 summarises the results of the tests for hypotheses 1-7.

An identical approach was applied in the case of testing the properties of the aggregated crime samples. A pre-test and Ttest or F-test were used to test the validity of the supposition that changes in crime will be consistent in New York City and London, as well as to explore further the properties of the aggregated samples as presented in Tables 8-13.

\footnotetext{
$4 \quad$ https://www1.nyc.gov/site/nypd/stats/crimestatistics/citywide-crime-stats.page

5 https://www.met.police.uk/sd/stats-and-data/met/crime-datadashboard/

6 https://www.covid19tracker.health.ny.gov

7 https://www.coronavirus.data.gov.uk
}

The mean of the aggregated crime incidents in the month $\mathrm{t}(\mathrm{t}=$ 1, 2, 3, 4 for March, April, May, June, respectively) was compared for 2019 and 2020 for New York City and London, where:

$$
\begin{aligned}
& \mathrm{H}_{0} \bar{N}_{1 t}^{2019}=\bar{N}_{1 t}^{2020} \quad(t=1,2,3,4) \\
& H_{\mathrm{a}} \bar{N}_{1 t}^{2019}>\bar{N}_{1 t}^{2020} \quad(t=1,2,3,4)
\end{aligned}
$$

Where $\bar{N}_{2 t}^{2019}$ is the mean of the crime incidents across all seven categories in London in the month $t(t=1,2,3,4$ for March, April, May, June, respectively) in 2019.

In continuation, the mean and variance statistics tests ( $\mathrm{t}$-stat and F-stat) for the crime incidents in NYC and London, respectively, were conducted for 2019 and 2020, for equal variances.

Represented numerically:

$$
\begin{aligned}
& \left(\mu_{2019}=\mu_{2020}\right) \Leftrightarrow\left(\mu_{2019}-\mu_{2020}=0\right) \\
& \left(\mu_{2019}>\mu_{2020}\right) \Leftrightarrow\left(\mu_{2019}-\mu_{2020}>0\right)
\end{aligned}
$$

As a follow-up, for unequal variances:

$$
\begin{aligned}
& \left(\mu_{2019}>\mu_{2020}\right) \Leftrightarrow\left(\mu_{2019}-\mu_{2020}>0\right) \\
& \left(\mu_{2019}>\mu_{2020}\right) \Leftrightarrow\left(\mu_{2019}-\mu_{2020}>0\right)
\end{aligned}
$$

Subsequently, a variance statistics test was conducted on the samples from 2019 and 2020 across the seven crime categories, using the variance comparison test as a pre-test for a two-sample comparison of means test (paired), where:

$$
\begin{aligned}
& \left(\sigma_{2019}^{2}-\sigma_{2020}^{2}\right) \Longleftrightarrow\left(\frac{\sigma_{2019}^{2}}{\sigma_{2020}^{2}}-1\right) \\
& \left(\sigma_{2019}^{2}>\sigma_{2020}^{2}\right) \Longleftrightarrow\left(\begin{array}{l}
\sigma_{2019}^{2}>1 \\
\sigma_{2020}^{2}>1
\end{array}\right)
\end{aligned}
$$

For Hypotheses 9-15, the OLS regression method was applied to test the correlation properties:

$$
\begin{array}{ll}
H 0: \rho\left(C_{1 t}, N_{1 i t}\right)=0 & (i=1,2, \ldots, 7) \\
H 1: \rho\left(C_{1 t}, N_{1 i t}\right) \neq 0 & (i=1,2, \ldots, 7)
\end{array}
$$

Where:

$C_{1 t}$ - is the number of COVID-19 cases in New York City in the month $t$ ( $t=1,2,3,4$ for March, April, May, June respectively) of 2020 .

$N_{1 i t}$ - is the number of crime incidents of a given category $i$ ( $i$ $=1,2, \ldots, 7$ for murder, rape, robbery, assault, burglary, grand larceny, grand larceny auto respectively) in New York City in the month $t(t=1,2,3,4$ for March, April, May, June respectively) of 2020 . 
The procedure was repeated for London.

$$
\begin{array}{ll}
H 0: \rho\left(C_{2 t}, N_{2 i t}\right)=0 & (i=1,2, \ldots, 7) \\
H 1: \rho\left(C_{2 t}, N_{2 i t}\right) \neq 0 & (i=1,2, \ldots, 7)
\end{array}
$$

Where:

$C_{2 t}$ - is the number of COVID-19 cases in London in the month $t(t=1,2,3,4$ for March, April, May, June respectively) of 2020 .

$N_{2 i t}$ - is the number of crime incidents of a given category $i$ ( $i$ $=1,2, \ldots, 7$ for homicide, rape, robbery, violence, burglary, theft, vehicle theft respectively) in London in the month $t$ ( $t=$ 1, 2, 3, 4 for March, April, May, June respectively) of 2020.

And lastly,

\begin{tabular}{|c|c|c|c|c|c|c|c|c|c|c|c|c|c|c|c|c|c|c|}
\hline NYC & \multicolumn{4}{|c|}{ March } & \multicolumn{4}{|c|}{ April } & \multicolumn{4}{|c|}{ May } & \multicolumn{4}{|c|}{ June } & Total & Mean \\
\hline Crime category & 2019 & 2020 & $+/-$ & $\Delta \%$ & 2019 & 2020 & $+/-$ & $\Delta \%$ & 2019 & 2020 & $+/-$ & $\Delta \%$ & 2019 & 2020 & $+/-$ & $\Delta \%$ & $+/-$ & $\Delta \%$ \\
\hline Murder & 21 & 22 & +1 & +4.8 & 23 & 31 & +8 & +34.8 & 19 & 34 & +15 & +78.9 & 30 & 39 & +9 & +30.0 & +33 & +37.1 \\
\hline Rape & 158 & 99 & -59 & -37.3 & 145 & 65 & -80 & -55.2 & 163 & 108 & -55 & -33.7 & 138 & 109 & -29 & -21.0 & -223 & -36.8 \\
\hline Robbery & 888 & 935 & +47 & +5.3 & 913 & 679 & -234 & -25.6 & 1088 & 776 & -312 & -28.7 & 1153 & 948 & -205 & -17.8 & -704 & -16.7 \\
\hline Assault & 1664 & 1546 & -118 & -7.1 & 1652 & 1130 & -522 & -31.6 & 1939 & 1582 & -357 & -18.4 & 1953 & 1947 & -6 & -0.3 & -1003 & -14.4 \\
\hline Burglary & 746 & 942 & +196 & +26.3 & 828 & 1090 & +262 & +31.6 & 861 & 1154 & +293 & +34.0 & 817 & 1783 & +966 & +118.2 & +1717 & +52.5 \\
\hline Grand Larceny & 3186 & 2640 & -546 & -17.1 & 3250 & 1566 & $\begin{array}{l}-1684 \\
\end{array}$ & -51.8 & 3608 & 2043 & -1565 & -43.4 & 3744 & 2317 & -1427 & -38.1 & -5222 & -37.6 \\
\hline Grand Larceny Auto & 303 & 490 & +187 & +61.7 & 351 & 560 & +209 & +59.5 & 397 & 665 & +268 & +67.5 & 462 & 696 & +234 & +50.6 & +898 & +59.9 \\
\hline Total $+/-$ and $\Delta \%$ & 6966 & 6674 & -292 & -4.2 & 7162 & 5121 & -2041 & -28.5 & 8075 & 6362 & -1713 & -21.2 & 8297 & 7839 & -458 & -5.5 & -4504 & -14.9 \\
\hline
\end{tabular}

$$
\begin{aligned}
& H_{0}: \quad \bar{N}_{1 t}^{2020}=\bar{N}_{2 t}^{2020} \quad(t=1,2,3,4) \\
& H_{1}: \bar{N}_{1 t}^{2020} \neq \bar{N}_{2 t}^{2020} \quad(t=1,2,3,4)
\end{aligned}
$$

Where:

\begin{tabular}{|c|c|c|c|c|c|c|c|c|c|c|c|c|c|c|c|c|c|c|}
\hline London & \multicolumn{4}{|c|}{ March } & \multicolumn{4}{|c|}{ April } & \multicolumn{4}{|c|}{ May } & \multicolumn{4}{|c|}{ June } & Total & Mean \\
\hline Crime category & 2019 & 2020 & $+/-$ & $\Delta \%$ & 2019 & 2020 & $+/-$ & $\Delta \%$ & 2019 & 2020 & $+/-$ & $\Delta \%$ & 2019 & 2020 & $+/-$ & $\Delta \%$ & $+/-$ & $\Delta \%$ \\
\hline Murder & 15 & 12 & -3 & -20.0 & 12 & 12 & 0 & 0.0 & 12 & 8 & -4 & -33.3 & 19 & 9 & -10 & -52.6 & -17 & -26.5 \\
\hline Rape & 664 & 556 & -108 & -16.3 & 646 & 446 & -200 & -31.0 & 647 & 507 & -140 & -21.6 & 672 & 625 & -47 & -7.0 & -495 & -19.0 \\
\hline Robbery & 3202 & 2713 & -489 & -15.3 & 3442 & 1102 & -2340 & -68.0 & 3327 & 1307 & -2020 & -60.7 & 3173 & 1713 & -1460 & -46.0 & -6309 & -47.5 \\
\hline Assault & 18727 & 17615 & -1112 & -5.9 & 17524 & 15416 & -2108 & -12.0 & 18879 & 17797 & -1082 & -5.7 & 19029 & 19095 & +66 & +0.3 & -4236 & -5.8 \\
\hline Burglary & 7222 & 5358 & -1864 & -25.8 & 6319 & 3663 & -2656 & -42.0 & 6412 & 3889 & -2523 & -39.3 & 6371 & 4320 & -2051 & -32.2 & -9094 & -34.8 \\
\hline Grand Lar & 21526 & 15014 & -6512 & -30.3 & 21689 & 7307 & -14382 & -66.3 & 21876 & 8984 & -12892 & -58.9 & 21282 & 11546 & -9736 & -45.7 & -43522 & -50.3 \\
\hline Grand Larceny Auto & 2596 & 2210 & -386 & -14.9 & 2650 & 1614 & $\begin{array}{l}-1036 \\
\end{array}$ & -39.1 & 2686 & 1763 & -923 & -34.4 & 2527 & 1940 & -587 & -23.2 & -2932 & -27.9 \\
\hline otal + & 53952 & 43478 & -10474 & -19.4 & 52282 & 29560 & -22722 & -43.5 & 53839 & 34255 & -19584 & -36.4 & 53073 & 39248 & -13825 & -26.0 & -66605 & -31.3 \\
\hline
\end{tabular}

Table 2: New York: a comparison of crime incidents in absolute numbers and crime rate change, March through June 2019-2020, respectively (own rendering, processed from source ${ }^{8}$ ).

Table 3: London: a comparison of crime incidents in absolute numbers and crime rate change, March through June 2019-2020, respectively (own rendering, processed from the source ${ }^{9}$ ).

$\bar{N}_{1 t}^{2020}$ is the average number of crime incidents across all seven categories (homicide, rape, robbery, violence, burglary, theft, vehicle theft) in New York City in the month $\mathrm{t}(\mathrm{t}=1,2$, 3, 4 for March, April, May, June respectively) of 2020.

$\bar{N}_{2 t}^{2 n 20}$ is the average number of crime incidents across all seven categories (homicide, rape, robbery, violence, burglary, theft, vehicle theft) in London in the month $\mathrm{t}(\mathrm{t}=1,2,3,4$ for March, April, May, June respectively) of 2020.

\section{FINDINGS}

The findings are presented for both cities and the periods under scrutiny in the established order, that is, New York City lowed by London and crime classification according to the opens with a monthly and total crime incidence on an absolute and rate basis, year-to-date change in the relevant months of 2019 compared to the same period in 2020 .

\subsection{Data Presentation}


Table 2 shows that, contrary to the assumptions, the number of incidents in New York City in three crime categories: murder, burglary and vehicle theft, did not drop after the introduction of lockdown. In comparison to March 2019, not only did the records show a higher volume of offences in March 2020 but they confirm that in these three categories, crime continued to rise throughout the lockdown period, month-on-month. While the number of observations for murder is small and therefore sensitive to any changes, which makes the relative comparison dubious, the total absolute number growth in these three categories: murder (+33 incidents), burglary $(+1717)$ and grand larceny auto $(+2788)$, respectively, came to +4538 , and alone constituted a rise of $87 \%$ in the four months in question (4538/5158). On the other hand, the total absolute number decrease in rape $(-223)$, robbery $(-704)$, assault $(-1003)$, grand larceny (-5222), respectively, came to -1930 and constituted a drop off of $14 \%(-1930 / 13788)$. In the case of robbery incidents, the downward trend did not come into effect until April. As an aggregate, the number of crime incidents in the four months under consideration went down by 4504 and almost 15\% (-4504/30500) respectively, year-on-year.
As can be inferred from Table 3, the nominal and percentage change in crime incidents in London followed the expectations. The sample size of the homicide category was too small to pass a clear judgment, even though the mean statistics shows a drop of $35.3 \%$. The largest drop off in crime was in the theft category, both nominally and relatively (43522 and $50.3 \%$, respectively), followed by burglary (-9094 and $34.8 \%$, respectively) and robbery (-6309 and $47.5 \%$, respectively). The total decline in crime incidents over the relevant months - as compared to 2019 - totalled -66 605 and $31 \%$ (-66 605/213146), respectively. The aggregated relative drop off in crime was twice as large in London as compared to New York (31/15). As in the case of New York City, this preliminary overview was subject to statistical testing.

To elucidate on the differences between the two cities under lockdown conditions, there follows a table summarising the change of crime rates year-on-year.

\begin{tabular}{|c|c|c|c|c|c|c|c|c|c|c|}
\hline \multirow{3}{*}{ Crime category } & \multicolumn{10}{|c|}{ Crime incidents in New York and London 2019-2020 change [\%] } \\
\hline & \multicolumn{2}{|c|}{ March } & \multicolumn{2}{|c|}{ April } & \multicolumn{2}{|c|}{ May } & \multicolumn{2}{|c|}{ June } & \multicolumn{2}{|c|}{ Total } \\
\hline & $\begin{array}{l}\text { New } \\
\text { York }\end{array}$ & London & $\begin{array}{l}\text { New } \\
\text { York }\end{array}$ & London & $\begin{array}{l}\text { New } \\
\text { York }\end{array}$ & London & $\begin{array}{l}\text { New } \\
\text { York }\end{array}$ & London & $\begin{array}{l}\text { New } \\
\text { York }\end{array}$ & London \\
\hline Murder (Homicide) & +5 & -20 & +35 & 0 & +79 & -33 & +30 & -53 & +35 & -29 \\
\hline Rape & -37 & -14 & -55 & -31 & -34 & -22 & -21 & -7 & -37 & -18 \\
\hline Robbery & +5 & -15 & -26 & -68 & -29 & -61 & -18 & -46 & -17 & -48 \\
\hline $\begin{array}{l}\text { Assault (Violence } \\
\text { against a Person) }\end{array}$ & -7 & -5 & -32 & -12 & -18 & -6 & 0 & 0 & -14 & -6 \\
\hline Burglary & +26 & -26 & +32 & -42 & +34 & -39 & +118 & -32 & +53 & -35 \\
\hline $\begin{array}{l}\text { Grand Larceny } \\
\text { (Theft) }\end{array}$ & -17 & -30 & -52 & -66 & -43 & -59 & -38 & -46 & -38 & -50 \\
\hline $\begin{array}{l}\text { Grand Larceny } \\
\text { Auto (Vehicle } \\
\text { Theft) }\end{array}$ & +62 & -15 & +60 & -39 & +68 & -34 & +51 & -23 & +59 & -28 \\
\hline Total & -4 & -19 & -28 & -43 & -21 & -36 & -6 & -26 & -15 & -31 \\
\hline
\end{tabular}

Table 4: London and New York: crime incidents 2019-2020, relative change year-to-year (source: as in Table 2 \& Table 3).

The year-to-year four-month comparison indicates that, with the exception of murder and burglary and car theft in New York City, in all the other crime categories as well as in burglary in London, the lockdown was associated with sudden drop offs in crime, with the total mean reduction of $15 \%$ and $31 \%$ in NYC and London, respectively, throughout the fourmonth period. The relative change in each month was respectively: 4.7 times, 1.5 times, 1.7 times and 4.3 times larger in London as compared to New York City. The lockdown was introduced a week later in London than in New York City, but it seemed to exert an almost immediate negative (i.e., preventive) effect on the crime rate in the former. It can be explained by the fact that the almost overnight result of the stay-home recommendation increased the presence of capable guardians, that is, the residents, thus preventing burglaries. Indeed, burglary in London remained at an approximately steady level of $-35 \%$ across all four months, which stood in contrast to NYC. On the other hand, the increase in the rates of murder, burglary and grand larceny auto across all four months in NYC, respectively, allows already to draw an initial inference that Hypotheses 1, 5 and 7 will not be validated for that city.

\subsection{Hypotheses 1-7: Analysis and Findings}

The following 14 figures illustrate the differences in the change trends (functions) for the selected crime categories in the period March through June 2020 as compared to the 
corresponding period in 2019. The dependent variable in each case is the number of the relevant crime incidents in absolute numbers. The blue curve describes the trend in 2019, whereas the orange curve depicts the corresponding trend in 2020. The graphs are positioned side-by-side, city-to-city, to illustrate the trend development in each crime category comparatively. The $\mathrm{y}$-axis has been adjusted to scale for each plot, given the variation in the count of recorded incidents, so that the presentation was consistent in size.

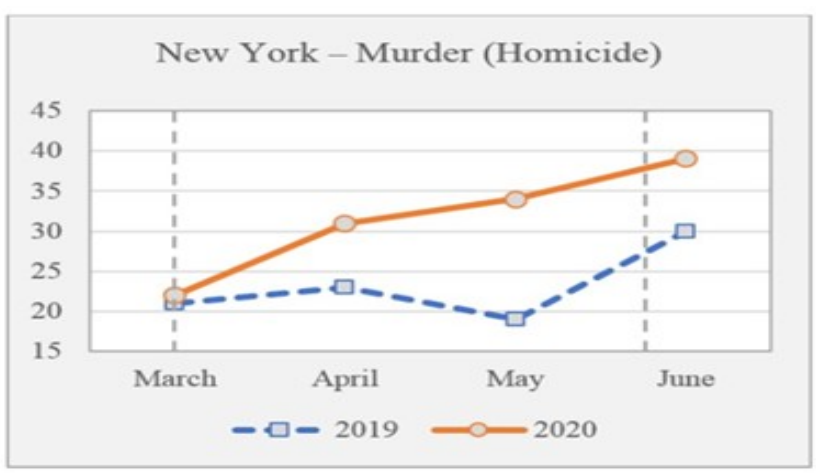

Figure 2: A comparison of murder incidents in New York, March-June 2019 and 2020.

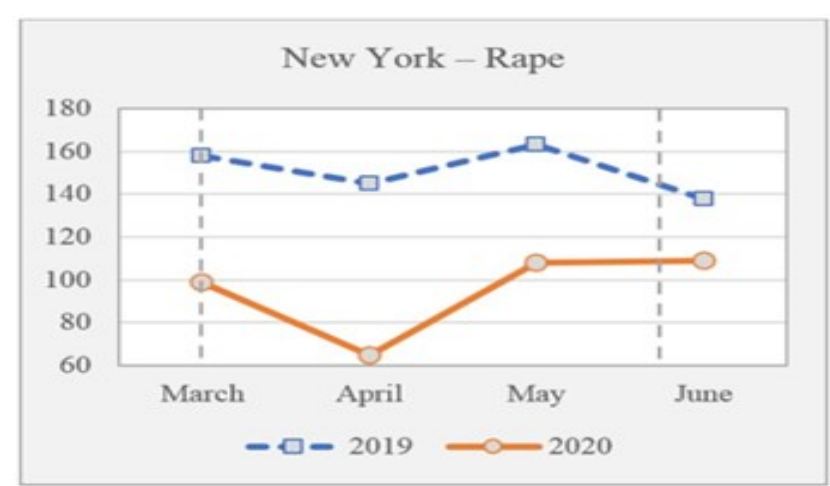

Figure 4: A comparison of rape incidents in New York, March-June 2019 and 2020.

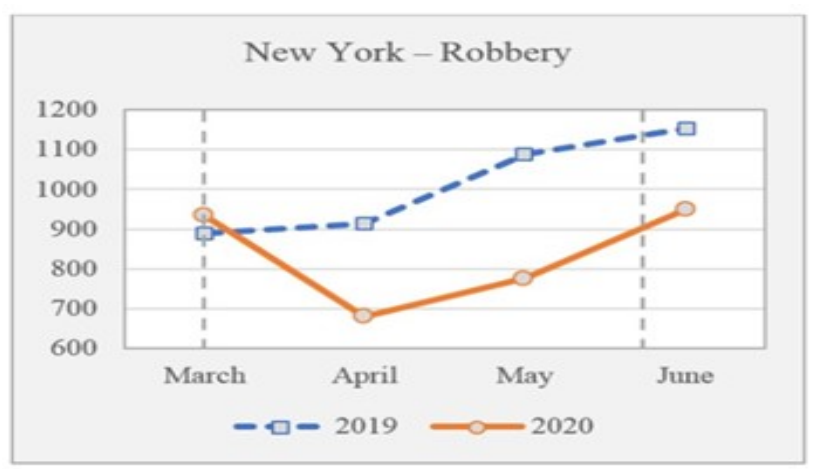

Figure 6: A comparison of robbery incidents in New York, March-June 2019 and 2020.
Two vertical lines have been included in each graph: the first one indicates the date of the lockdown introduction, and the second one - its lifting. Since it can be assumed that the labels on the horizontal line axis (March, April, May, June) mark the middle of the given month (the 15th or the 16th day), both the beginning (March 16/23 respectively) and the easing of the lockdown (June 8/15 respectively) are also assumed to stay within the horizontal axis limits. The source for Figure: 2, 4, 6, 8, 10, 12 and 14 is as in Table 2; the source for Figures 3, 5, 7, $9,11,13$ and 15 is as in Table 3 .

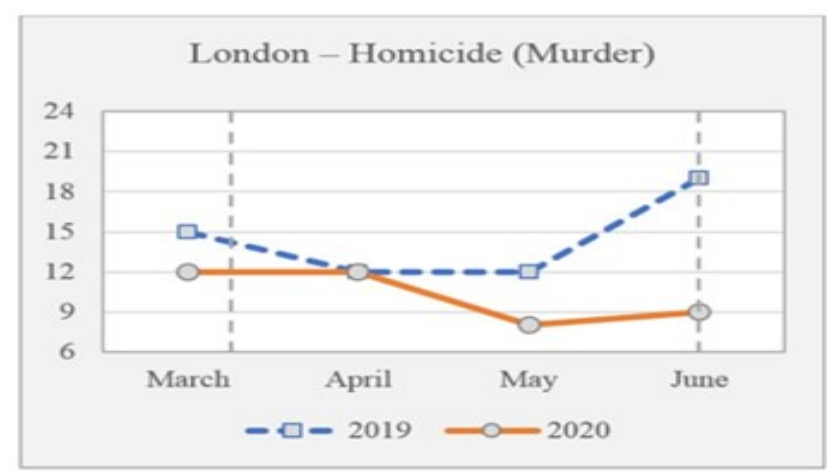

Figure 3: A comparison of homicide incidents in London, March-June 2019 and 2020.

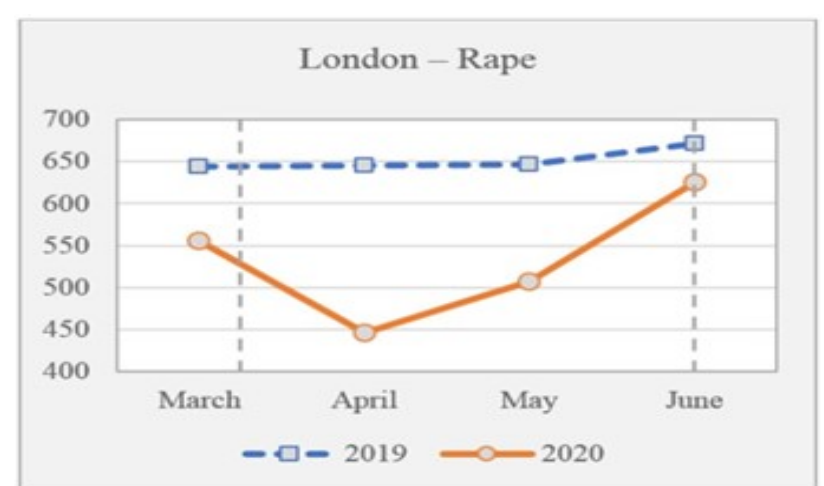

Figure 5: A comparison of rape incidents in London, MarchJune 2019 and 2020.

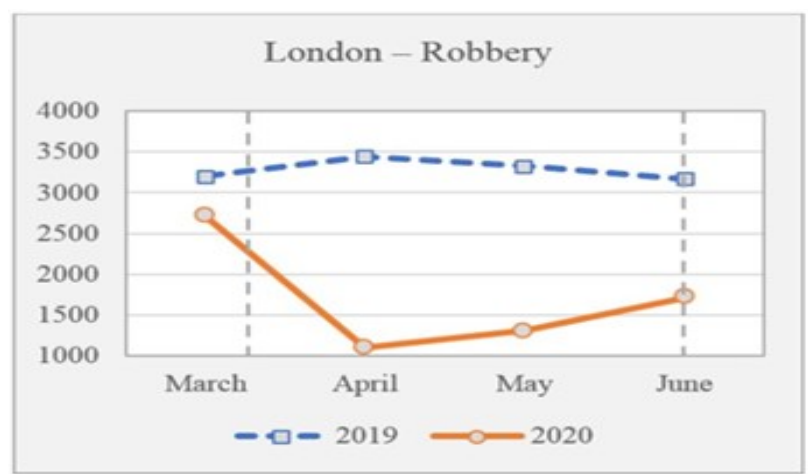

Figure 7: A comparison of robbery incidents in London, March-June 2019 and 2020. 


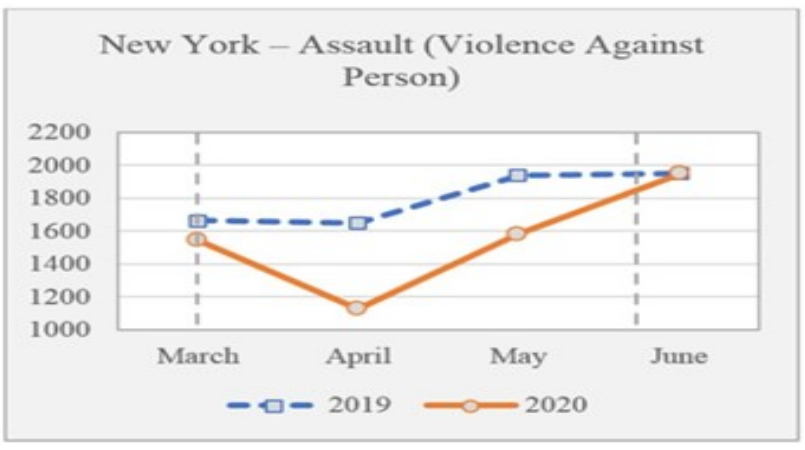

Figure 8: A comparison of assault incidents in New York, March-June 2019 and 2020.

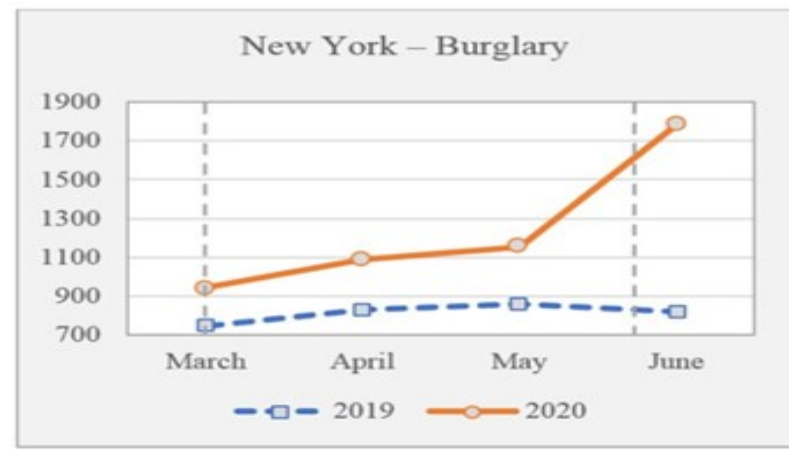

Figure 10: A comparison of burglary incidents in New York, March-June 2019 and 2020.

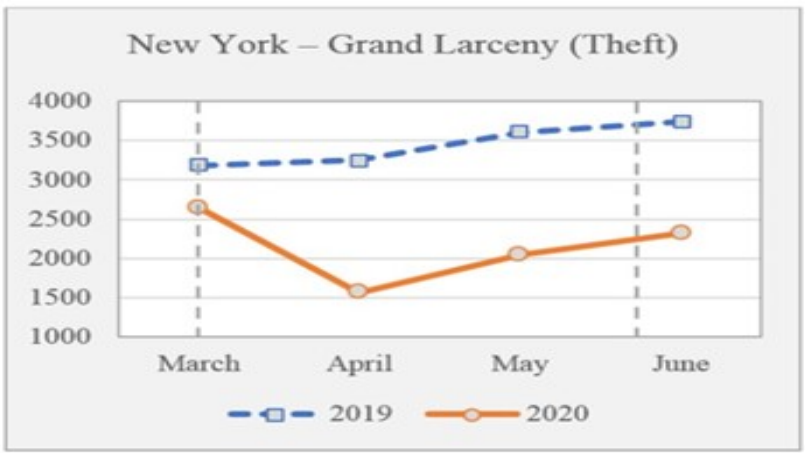

Figure 12: A comparison of grand larceny incidents in New York, March-June 2019 and 2020.

New York - Grand Larceny Auto (Vehicle Theft)

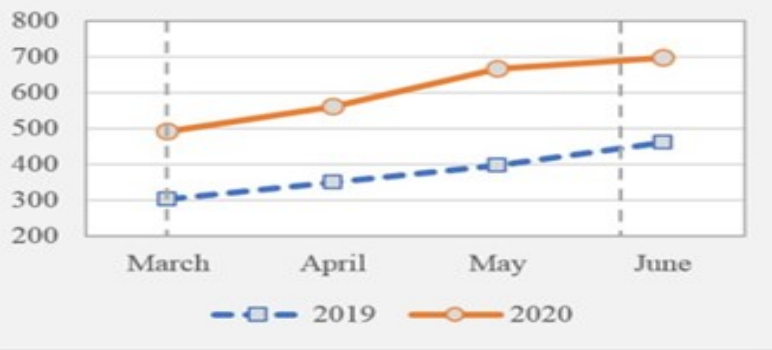

Figure 14: A comparison of grand larceny auto incidents in New York, March-June 2019 and 2020.

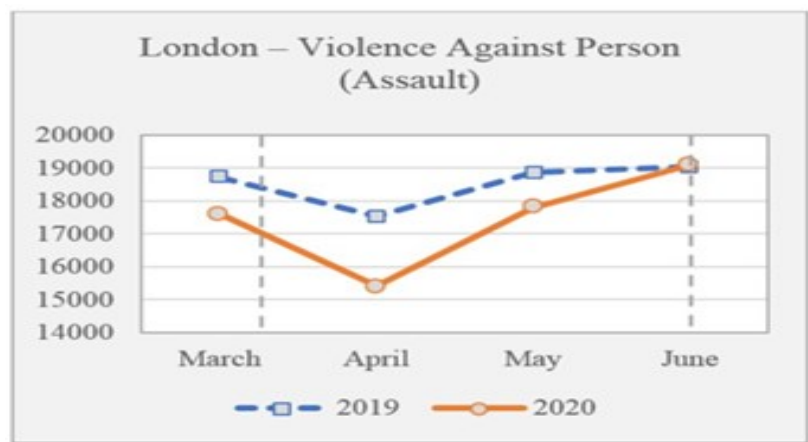

Figure 9: A comparison of violence against person incidents in London, March-June 2019 and 2020.

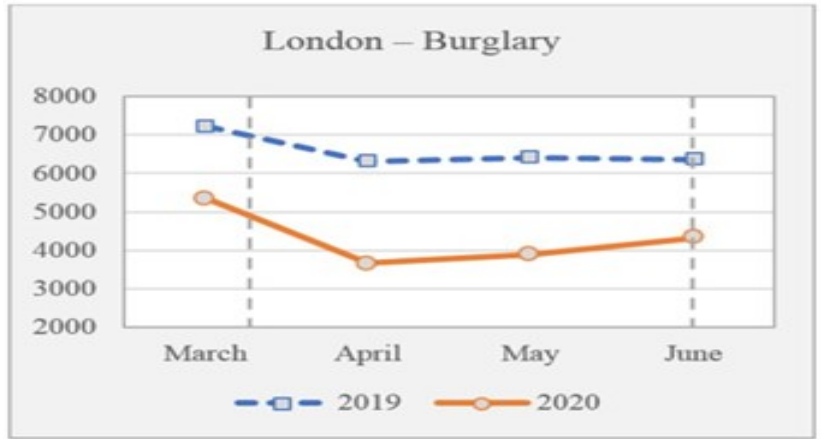

Figure 11: A comparison of burglary incidents in London, March-June 2019 and 2020.

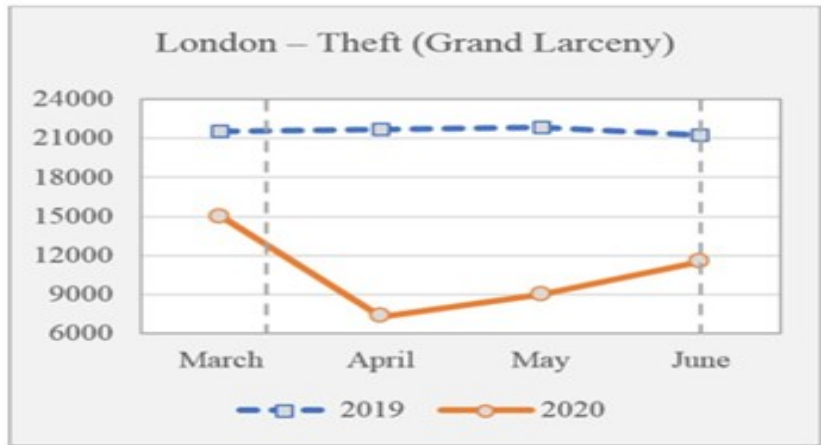

Figure 13: A comparison of theft incidents in London, MarchJune 2019 and 2020.

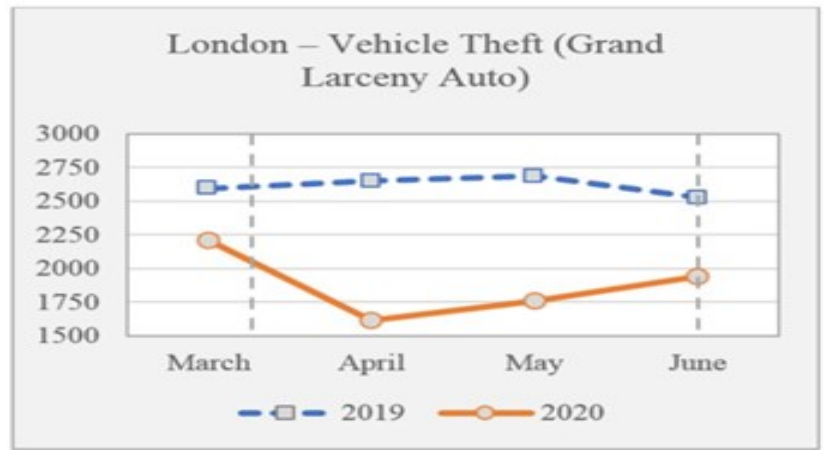

Figure 15: A comparison of vehicle theft incidents in London, March-June 2019 and 2020. 
The analysis started a with comparison of variance test, used as a preliminary test for the comparison of means test (paired), which was conducted in two versions - for equal and unequal group variances (in two samples for 2019 data and 2020 data). The appropriate version of the test was applied according to the relevant pre-test results. Namely, if the comparison of variance result was significant (significant $(\mathrm{p}<0.05)$, the comparison of means test was conducted with the Welch's correction for unequal variances, whereas if the variance quotient was not significant $(\mathrm{p}>0.05)$, the equality test was applied. The initial test results for both NYC and London are included in the Appendix.

\begin{tabular}{|c|c|c|c|c|c|c|c|c|c|}
\hline \multirow{2}{*}{$\begin{array}{l}\text { NYC, } \\
\text { hypothesis } \\
\text { number } \\
\text { and crime } \\
\text { category }\end{array}$} & \multicolumn{3}{|c|}{ Statistics for 2019} & \multicolumn{3}{|c|}{ Statistics for 2020} & \multicolumn{3}{|c|}{ Comparison of means test } \\
\hline & $\mathrm{N}$ & Mean & SD & $\mathrm{N}$ & Mean & SD & t-stat & p-value & Final result \\
\hline H1: Murder & 4 & 23 & 2 & 4 & 32 & 4 & -1.92 & 0.0517 & not significant $(\mathrm{p}>0.05)$ \\
\hline H2: Rape & 4 & 151 & 6 & 4 & 95 & 10 & 4.71 & 0.0016 & significant $(\mathrm{p}<0.05)$ \\
\hline H3: Robbery & 4 & 1011 & 65 & 4 & 835 & 65 & 1.91 & 0.0520 & not significant $(\mathrm{p}>0.05)$ \\
\hline H4: Assault & 4 & 1902 & 83 & 4 & 1551 & 167 & 1.34 & 0.1139 & not significant $(p>0.05)$ \\
\hline H5: Burglary & 4 & 813 & 24 & 4 & 1242 & 186 & -2.29 & 0.0514 & not significant $(\mathrm{p}>0.05)$ \\
\hline $\begin{array}{l}\text { H6: Grand } \\
\text { Larceny }\end{array}$ & 4 & 3447 & 136 & 4 & 2142 & 227 & 4.93 & 0.0013 & significant $(\mathrm{p}<0.05)$ \\
\hline $\begin{array}{l}\text { H7: Grand } \\
\text { Larceny Auto }\end{array}$ & 4 & 378 & 34 & 4 & 603 & 48 & -3.85 & 0.0042 & significant $(\mathrm{p}<0.05)$ \\
\hline Total & 28 & 1089 & 215 & 28 & 928 & 144 & 0.62 & 0.2689 & not significant $(p>0.05)$ \\
\hline
\end{tabular}

Table 5: A two-sample comparison of means test (paired) with Welch's correction for unequal variances (if necessary and applicable), NYC 2019-2020, Hypotheses 1-7, N is the number of months.

As can be inferred from Table 5, Hypotheses 2 and 6 (rape and grand larceny) have been validated. Hypothesis 3 (robbery) shows a p-value of 0.052 , while Hypothesis 5 (burglary) indicates a p-value of 0.051 . These hypotheses should be retested on a more detailed sample (daily crime records) to draw more precise conclusions. In the case of Hypothesis 7 (grand larceny auto) the p-value is smaller than 0.05 , however the $t$ stat coefficient is negative, therefore this hypothesis cannot be validated. In fact, there was a rise in this crime category, as indicated by the results in Tables 2 and 4. After the equality of means tests analysis it can be concluded that The Spring 2020 Lockdown in NYC only had a clear crime reducing effect in the rape and grand larceny categories. Nevertheless, the data does not provide enough support to formulate the opposite conclusion, i.e., that it is possible to deduce that lockdown had a crime inducing effect on the crime count in NYC.

An analogous procedure was applied in the case of London.

\begin{tabular}{|c|c|c|c|c|c|c|c|c|c|}
\hline $\begin{array}{l}\text { London, } \\
\text { hypothesis } \\
\text { number \& } \\
\text { crime } \\
\text { category }\end{array}$ & \multicolumn{3}{|c|}{ Statistics for 2019} & \multicolumn{3}{|c|}{ Statistics for 2020} & \multicolumn{3}{|c|}{ Mean comparison test } \\
\hline H1: Homicide & 4 & 15 & 2 & 4 & 10 & 1 & 2.18 & 0.0362 & significant $(\mathrm{p}<0.05)$ \\
\hline H2: Rape & 4 & 652 & 7 & 4 & 534 & 38 & 3.09 & 0.0249 & significant $(\mathrm{p}<0.05)$ \\
\hline $\begin{array}{l}\text { H4: Violence } \\
\text { Against Person }\end{array}$ & 4 & 18540 & 344 & 4 & 17481 & 763 & 1.27 & 0.1264 & not significant $(\mathrm{p}>0.05)$ \\
\hline H5: Burglary & 4 & 6581 & 215 & 4 & 4308 & 376 & 5.25 & 0.0010 & significant $(\mathrm{p}<0.05)$ \\
\hline H6: Theft & 4 & 21593 & 126 & 4 & 10713 & 1678 & 6.47 & 0.0036 & significant $(\mathrm{p}<0.05)$ \\
\hline
\end{tabular}

Table 6: A two-sample comparison of means test (paired) with Welch's correction for unequal variances (if necessary and applicable), London, 2019-2020, Hypotheses 1-7, $\mathrm{N}$ is the number of months. 
In the case of London, only Hypothesis 4 was not validated. Lockdown had a crime reducing effect on crime, with the exception of violence against a person. Table 7 presents the

\begin{tabular}{|l|l|l|}
\hline Hypothesis number and crime category & New York & London \\
\hline H1 Murder/ Homicide & Not validated & Validated \\
\hline H2 Rape & Validated & Validated \\
\hline H3 Robbery & Not validated & Validated \\
\hline H4 Assault/ Violence Against a Person & Not validated & Validated \\
\hline H5 Burglary & Not validated & Validated \\
\hline H6 Grand Larceny/ Theft & Validated & Validated \\
\hline H7 Grand Larceny Auto/ Vehicle Theft & Not validated & \\
\hline
\end{tabular}

ultimate summary of the findings, by validating or disproving Hypotheses 1-7.

Table 7: Hypotheses 1-7, validation.

In continuation, the same procedure was performed for all crime type incidents grouped together.

The aggregated figure was the total sum of all relevant crime incidents in each relevant month. Thus, in Tables 8 and 9, $\mathrm{N}$ is the aggregated number of the crime categories (7). Again, the initial analysis started with an equality of variances test, used as a preliminary test for the comparison of means test (paired) across crime categories, which was conducted in two versions - for equal and unequal group variances (in two samples for 2019 data and 2020 data).

\begin{tabular}{|l|l|l|l|l|l|l|l|l|l|}
\hline \multirow{2}{*}{ Month } & \multicolumn{3}{|c|}{ Statistics for 2019 } & \multicolumn{4}{c|}{ Statistics for 2020 } & \multicolumn{3}{c|}{ Comparison of means test } \\
\cline { 2 - 10 } & N & Mean & SD & N & Mean & SD & t-stat & p-value & Final result \\
\hline March & 7 & 995 & 1114 & 7 & 953 & 914 & 0.08 & 0.470 & not significant $(\mathrm{p}>0.05)$ \\
\hline April & 7 & 1023 & 1128 & 7 & 732 & 570 & 0.61 & 0.276 & not significant $(\mathrm{p}>0.05)$ \\
\hline May & 7 & 1154 & 1263 & 7 & 909 & 740 & 0.44 & 0.333 & not significant $(\mathrm{p}>0.05)$ \\
\hline June & 7 & 1185 & 1306 & 7 & 1120 & 909 & 0.11 & 0.458 & not significant $(\mathrm{p}>0.05)$ \\
\hline Total & 28 & 1089 & 1140 & 28 & 928 & 763 & 0.62 & 0.269 & not significant $(\mathrm{p}>0.05)$ \\
\hline
\end{tabular}

Table 8: New York: a pre-test for a two-sample comparison of means test (paired), $\mathrm{N}$ is the aggregated number of crime categories.

\begin{tabular}{|l|l|l|l|l|l|l|l|l|l|}
\hline \multirow{2}{*}{ Month } & \multicolumn{3}{|c|}{ Statistics for 2019 } & \multicolumn{3}{c|}{ Statistics for 2020 } & \multicolumn{3}{c|}{ Comparison of means test } \\
\cline { 2 - 10 } & $\mathrm{N}$ & Mean & SD & $\mathrm{N}$ & Mean & SD & t-stat & p-value & Final result \\
\hline March & 7 & 7705 & 8833 & 7 & 6211 & 7152 & 0.35 & 0.367 & not significant $(\mathrm{p}>0.05)$ \\
\hline April & 7 & 7469 & 8624 & 7 & 4223 & 5533 & 0.84 & 0.209 & not significant $(\mathrm{p}>0.05)$ \\
\hline May & 7 & 7691 & 8951 & 7 & 4894 & 6455 & 0.67 & 0.258 & not significant $(\mathrm{p}>0.05)$ \\
\hline June & 7 & 7582 & 8852 & 7 & 5607 & 7114 & 0.46 & 0.327 & not significant $(\mathrm{p}>0.05)$ \\
\hline Total & 28 & 7612 & 8312 & 28 & 5234 & 6265 & 1.21 & 0.116 & not significant $(\mathrm{p}>0.05)$ \\
\hline
\end{tabular}

Table 9: London: a pre-test for a two-sample comparison of means test (paired), $\mathrm{N}$ is the aggregated number of crime categories.

The results indicate that the mean of the aggregated crime incidents in the respective months and in total in 2019 was not larger than the mean in 2020, both for New York City and London.

\begin{tabular}{|l|l|l|l|l|l|l|l|l|l|}
\hline \multirow{2}{*}{ Month } & \multicolumn{3}{|c|}{ Statistics for 2019 } & \multicolumn{4}{c|}{ Statistics for 2020 } & \multicolumn{3}{c|}{ Comparison of means test } \\
\cline { 2 - 10 } & N & Mean & SD & N & Mean & SD & t-stat & p-value & Final result \\
\hline March & 7 & 995 & 1114 & 7 & 953 & 914 & 0.08 & 0.470 & not significant $(\mathrm{p}>0.05)$ \\
\hline April & 7 & 1023 & 1128 & 7 & 732 & 570 & 0.61 & 0.278 & not significant $(\mathrm{p}>0.05)$ \\
\hline May & 7 & 1154 & 1263 & 7 & 909 & 740 & 0.44 & 0.334 & not significant $(\mathrm{p}>0.05)$ \\
\hline June & 7 & 1185 & 1306 & 7 & 1120 & 909 & 0.11 & 0.458 & not significant $(\mathrm{p}>0.05)$ \\
\hline
\end{tabular}

There followed a test of comparison of means test in 2019 and 2020 across crime categories using a comparison of means test (paired) for unequal variances (Table 10-13). 


\begin{tabular}{|l|l|l|l|l|l|l|l|l|l|}
\hline Total & 28 & 1089 & 1140 & 28 & 928 & 763 & 0.62 & 0.269 & not significant $(\mathrm{p}>0.05)$ \\
\hline
\end{tabular}

Table 10: New York: a comparison of means test in 2019 and 2020 across crime categories for unequal variances, $\mathrm{N}$ is the number of crime categories.

\begin{tabular}{|l|l|l|l|l|l|l|l|l|l|}
\hline \multirow{2}{*}{ Month } & \multicolumn{4}{|c|}{ Statistics for 2019 } & \multicolumn{4}{c|}{ Statistics for 2020 } & \multicolumn{3}{c|}{ Comparison of means test } \\
\cline { 2 - 10 } & $\mathrm{N}$ & Mean & SD & N & Mean & SD & t-stat & p-value & Final result \\
\hline March & 7 & 7705 & 8833 & 7 & 6211 & 7152 & 0.35 & 0.367 & not significant $(\mathrm{p}>0.05)$ \\
\hline April & 7 & 7469 & 8624 & 7 & 4223 & 5533 & 0.84 & 0.211 & not significant $(\mathrm{p}>0.05)$ \\
\hline May & 7 & 7691 & 8951 & 7 & 4894 & 6455 & 0.67 & 0.258 & not significant $(\mathrm{p}>0.05)$ \\
\hline June & 7 & 7582 & 8852 & 7 & 5607 & 7114 & 0.46 & 0.327 & not significant $(\mathrm{p}>0.05)$ \\
\hline Total & 28 & 7612 & 8312 & 28 & 5234 & 6265 & 1.21 & 0.116 & not significant $(\mathrm{p}>0.05)$ \\
\hline
\end{tabular}

Table 11: London: a comparison of means test in 2019 and 2020 across crime categories for unequal variances, $\mathrm{N}$ is the number of crime categories.

\begin{tabular}{|l|l|l|l|l|l|l|l|l|l|}
\hline \multirow{2}{*}{ Month } & \multicolumn{3}{|c|}{ Statistics for 2019 } & \multicolumn{4}{c|}{ Statistics for 2020 } & \multicolumn{3}{c|}{ Variance ratio test } \\
\cline { 2 - 10 } & $\mathrm{N}$ & Mean & SD & N & Mean & SD & F-stat & p-value & Final result \\
\hline March & 7 & 995 & 1114 & 7 & 953 & 914 & 1.49 & 0.321 & not significant $(\mathrm{p}>0.05)$ \\
\hline April & 7 & 1023 & 1128 & 7 & 732 & 570 & 3.91 & 0.061 & not significant $(\mathrm{p}>0.05)$ \\
\hline May & 7 & 1154 & 1263 & 7 & 909 & 740 & 2.92 & 0.109 & not significant $(\mathrm{p}>0.05)$ \\
\hline June & 7 & 1185 & 1306 & 7 & 1120 & 909 & 2.06 & 0.200 & not significant $(\mathrm{p}>0.05)$ \\
\hline Total & 28 & 1089 & 1140 & 28 & 928 & 763 & 2.23 & 0.021 & significant $(\mathrm{p}<0.05)$ \\
\hline
\end{tabular}

Table 12: New York: a pre-test for a two-sample comparison of means test (paired), $\mathrm{N}$ is the aggregated number of crime categories.

\begin{tabular}{|l|l|l|l|l|l|l|l|l|l|}
\hline \multirow{2}{*}{ Month } & \multicolumn{4}{|c|}{ Statistics for 2019 } & \multicolumn{4}{c|}{ Statistics for 2020 } & \multicolumn{3}{c|}{ Variance ratio test } \\
\cline { 2 - 10 } & N & Mean & SD & N & Mean & SD & F-stat & p-value & Final result \\
\hline March & 7 & 7705 & 8833 & 7 & 6211 & 7152 & 1.53 & 0.311 & not significant $(\mathrm{p}>0.05)$ \\
\hline April & 7 & 7469 & 8624 & 7 & 4223 & 5533 & 2.43 & 0.152 & not significant $(\mathrm{p}>0.05)$ \\
\hline May & 7 & 7691 & 8951 & 7 & 4894 & 6455 & 1.92 & 0.223 & not significant $(\mathrm{p}>0.05)$ \\
\hline June & 7 & 7582 & 8852 & 7 & 5607 & 7114 & 1.55 & 0.304 & not significant $(\mathrm{p}>0.05)$ \\
\hline Total & 28 & 7612 & 8312 & 28 & 5234 & 6265 & 1.76 & 0.074 & not significant $(\mathrm{p}>0.05)$ \\
\hline
\end{tabular}

Table 13: London: a pre-test for a two-sample comparison of means test (paired), $\mathrm{N}$ is the aggregated number of crime categories.

The results indicate that the mean of the aggregated crime incidents in the respective months and in total in 2019 was not larger than the mean for the crime aggregates in both cities in 2020 .

The equality of variances test results also indicate that the variance of the aggregated number of the incidents in the seven crime categories in 2019 was not significantly different in each consecutive month from that of 2020 in both cities. However, the results of the test conducted on the aggregate for the four months in NYC show that the 2020 variance was smaller than in 2019, hence indicating the smaller dispersion of crime in that year.

The null hypothesis in this test assumes that the variance/dispersion of the number of crime incidents in 2020 does not differ significantly in relation to the previous year, whereas the alternative hypothesis states that the variance/dispersion is significantly lower in 2020 than in the previous year.

The results for the data from New York City in March 2019/2020 indicate that with the significance level of $\alpha=0.05$ the dispersion of the number of crime incidents is comparable in both analysed years (test statistics: F-stat $=1.49$ with pvalue $=0.321>0.05$ ), which means that there are no grounds for rejecting the null hypothesis. Similar tests were conducted in April $(\mathrm{F}$-stat $=3.91$ with p-value $=0.061>0.05)$, May $(\mathrm{F}$ stat $=2.92$ with p-value $=0.109>0.05)$ and June $(\mathrm{F}$-stat $=$ 2.06 with $p$-value $=0.200>0.05)$. The variance value in both years did not change significantly at the significance level of $5 \%$. However, assuming the significance level of $10 \%$, the decision in regard to the data from April would change, and one would claim that the dispersion of the number of crime incidents was significantly lower in 2020 than in 2019. 


\subsection{Hypothesis 8: Analysis and Findings}

An analogous procedure was applied in the case of Hypothesis 8. Firstly, a comparison of crime tendencies in 2020 was presented graphically (Figure 16).

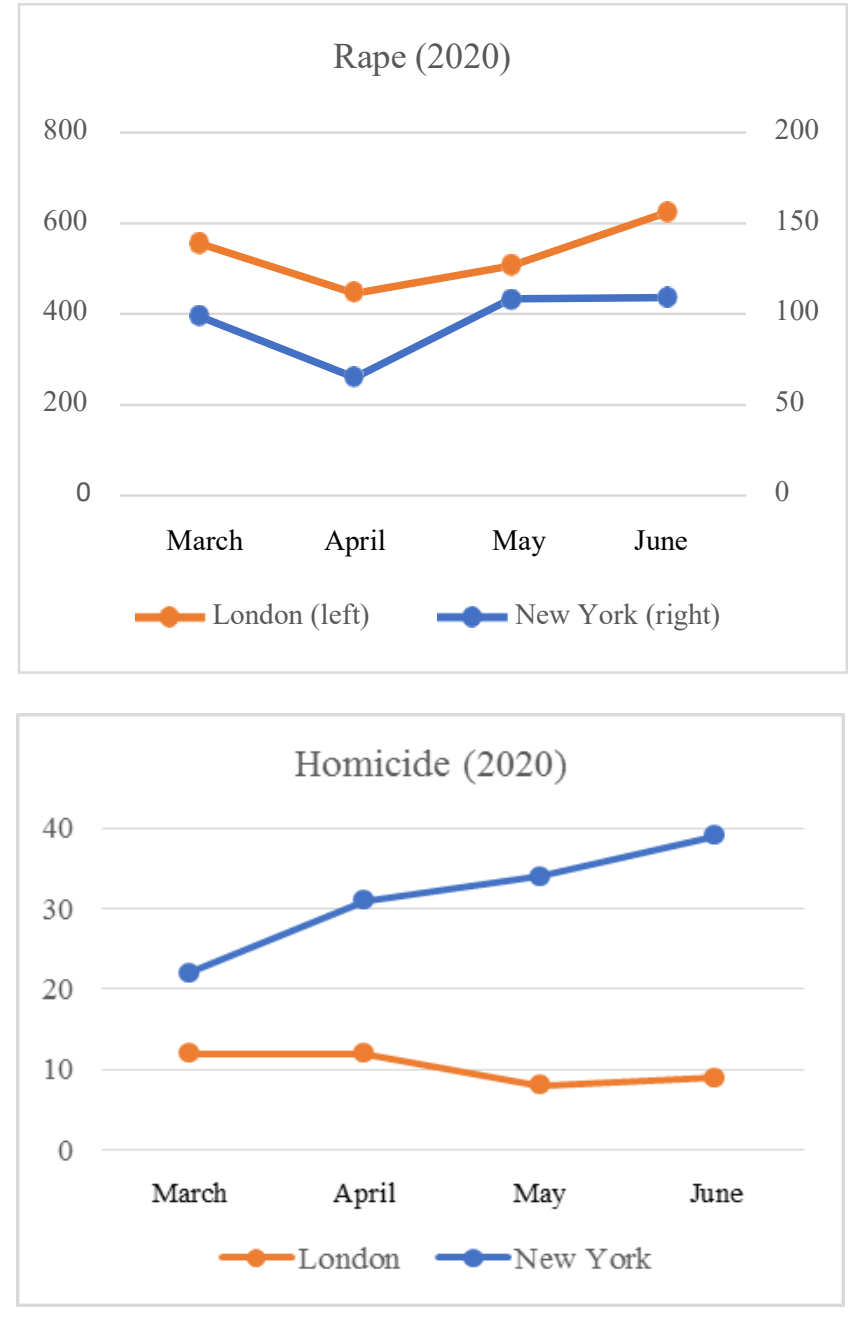

\section{Robbery (2020)}

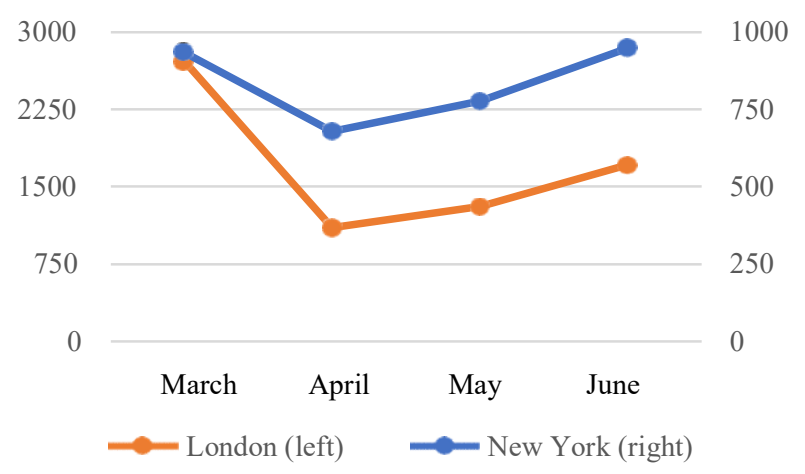

Assault (2020)

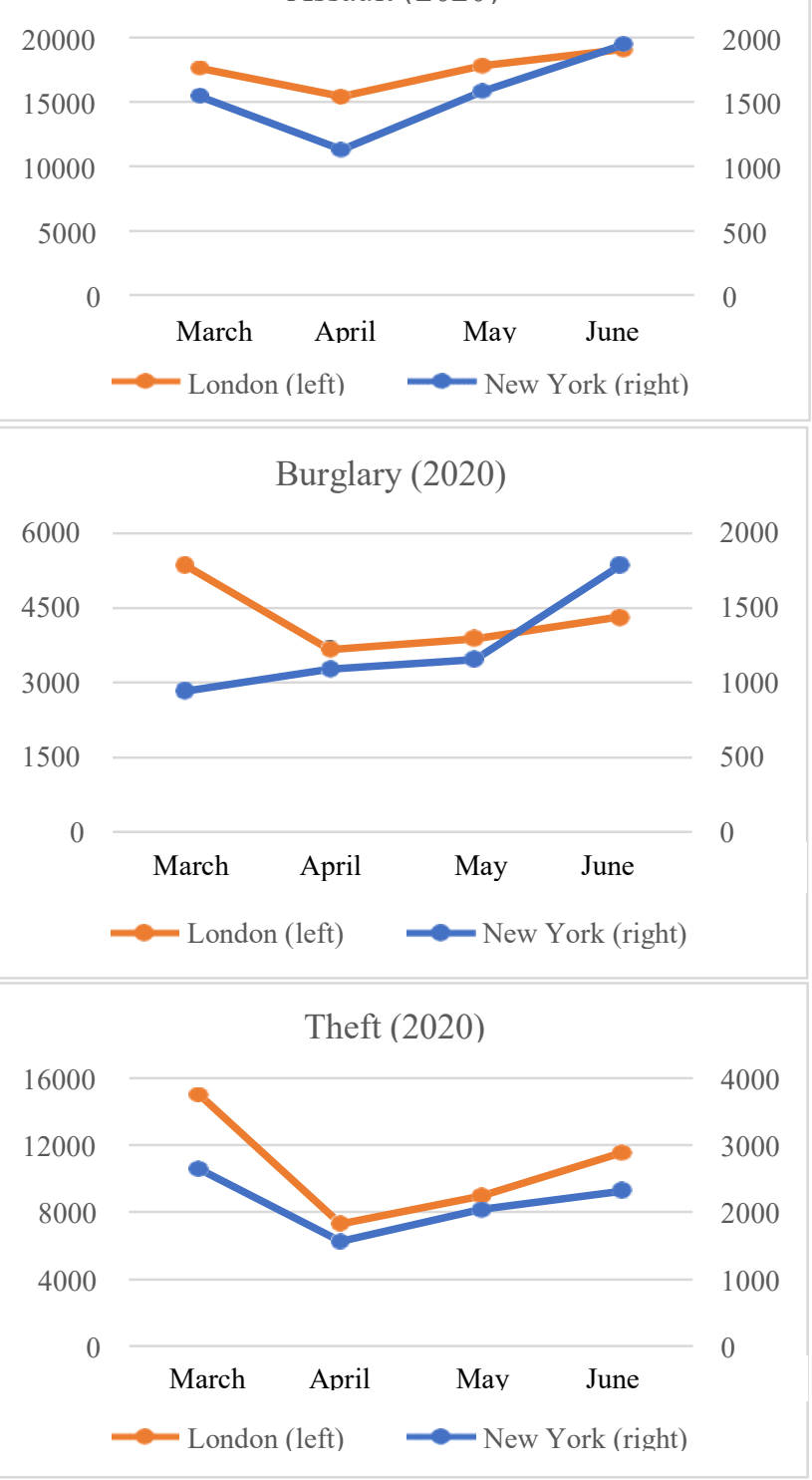

Vehicle theft (2020)

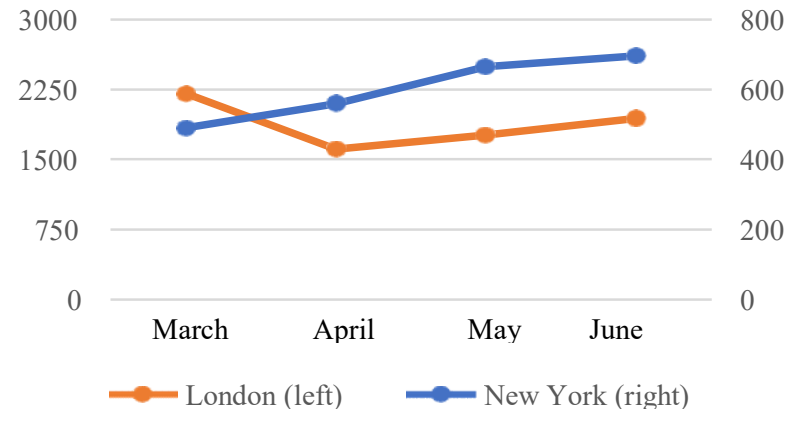

Figure 16: A comparison of the crime trends in absolute numbers, New York and London, 2020 (source: as in Table 2 \& Table 3). 
An initial assessment of the respective functions leads to the conclusion that crime trends under lockdown in the two cities were dissimilar, with the exception of robbery and theft. This inference was subsequently subjected to statistical tests. $\mathrm{N}$ is the number of months (Table $14 \& 15$ ).

\begin{tabular}{|c|c|c|c|c|c|c|c|c|c|}
\hline \multirow{2}{*}{$\begin{array}{l}\text { Hypothesis 8: } \\
\text { Crime category (2019) }\end{array}$} & \multicolumn{3}{|c|}{ Statistics for NYC } & \multicolumn{3}{|c|}{ Statistics for London } & \multicolumn{3}{|c|}{ Variance ratio test } \\
\hline & $\mathrm{N}$ & Mean & SD & $\mathrm{N}$ & Mean & SD & F-stat & p-value & Final result \\
\hline H8: Murder (Homicide) & 4 & 23 & 2 & 4 & 15 & 2 & 2.1 & 0.2810 & $\begin{array}{l}\text { not significant } \\
(\mathrm{p}>0.05)\end{array}$ \\
\hline H8: Rape & 4 & 151 & 6 & 4 & 652 & 7 & 1.3 & 0.4128 & $\begin{array}{l}\text { not significant } \\
(\mathrm{p}>0.05)\end{array}$ \\
\hline H8: Robbery & 4 & 1011 & 65 & 4 & 3286 & 62 & 1.1 & 0.4672 & $\begin{array}{l}\text { not significant } \\
(\mathrm{p}>0.05)\end{array}$ \\
\hline $\begin{array}{l}\text { H8: Assault (Violence Against } \\
\text { Person) }\end{array}$ & 4 & 1802 & 83 & 4 & 18540 & 344 & 17.1 & 0.0217 & $\begin{array}{l}\text { significant (p } \\
<0.05)\end{array}$ \\
\hline H8: Burglary & 4 & 813 & 24 & 4 & 6581 & 215 & 78.5 & 0.0024 & $\begin{array}{l}\text { significant (p } \\
<0.05)\end{array}$ \\
\hline H8: Grand Larceny (Theft) & 4 & 3447 & 136 & 4 & 21593 & 126 & 1.2 & 0.4528 & $\begin{array}{l}\text { not significant } \\
(\mathrm{p}>0.05)\end{array}$ \\
\hline $\begin{array}{l}\text { H8: Grand Larceny Auto } \\
\text { (Vehicle Theft) }\end{array}$ & 4 & 378 & 34 & 4 & 2615 & 35 & 1.0 & 0.4864 & $\begin{array}{l}\text { not significant } \\
(p>0.05)\end{array}$ \\
\hline Total & 28 & 1089 & 215 & 28 & 7612 & 1571 & 53.2 & 0.0000 & $\begin{array}{l}\text { significant (p } \\
<0.05)\end{array}$ \\
\hline
\end{tabular}

Table 14: An equality of variances test: a pre-test for a two-sample comparison of means test (paired), New York and London, 2019.

\begin{tabular}{|c|c|c|c|c|c|c|c|c|c|}
\hline \multirow{2}{*}{$\begin{array}{l}\text { Hypothesis 8: } \\
\text { Crime category } \\
(2020)\end{array}$} & \multicolumn{3}{|c|}{ Statistics for NYC } & \multicolumn{3}{|c|}{ Statistics for London } & \multicolumn{3}{|c|}{ Variance ratio test } \\
\hline & $\mathrm{N}$ & Mean & $\mathrm{SD}$ & $\mathrm{N}$ & Mean & SD & F-stat & p-value & Final result \\
\hline H8: Murder (Homicide) & 4 & 32 & 4 & 4 & 10 & 1 & 12.00 & 0.0354 & $\begin{array}{l}\text { significant }(\mathrm{p}< \\
0.05)\end{array}$ \\
\hline H8: Rape & 4 & 95 & 10 & 4 & 534 & 38 & 13.46 & 0.0302 & $\begin{array}{l}\text { significant }(\mathrm{p}< \\
0.05)\end{array}$ \\
\hline H8: Robbery & 4 & 835 & 65 & 4 & 1709 & 358 & 30.41 & 0.0096 & $\begin{array}{l}\text { significant }(\mathrm{p}< \\
0.05)\end{array}$ \\
\hline $\begin{array}{l}\text { H8: Assault (Violence } \\
\text { Against Person) }\end{array}$ & 4 & 1551 & 167 & 4 & 17481 & 763 & 20.85 & 0.0164 & $\begin{array}{l}\text { significant }(\mathrm{p}< \\
0.05)\end{array}$ \\
\hline H8: Burglary & 4 & 1242 & 186 & 4 & 4308 & 376 & 4.10 & 0.1385 & $\begin{array}{l}\text { not significant }(p \\
>0.05)\end{array}$ \\
\hline $\begin{array}{l}\text { H8: Grand Larceny } \\
\text { (Theft) }\end{array}$ & 4 & 2142 & 227 & 4 & 10713 & 1678 & 54.47 & 0.0041 & $\begin{array}{l}\text { significant }(\mathrm{p}< \\
0.05)\end{array}$ \\
\hline $\begin{array}{l}\text { H8: Grand Larceny Auto } \\
\text { (Vehicle Theft) }\end{array}$ & 4 & 603 & 48 & 4 & 1882 & 128 & 7.26 & 0.0688 & $\begin{array}{l}\text { not significant }(\mathrm{p} \\
>0.05)\end{array}$ \\
\hline Total & 28 & 928 & 144 & 28 & 5234 & 1184 & 67.36 & 0.0000 & $\begin{array}{l}\text { significant }(\mathrm{p}< \\
0.05)\end{array}$ \\
\hline
\end{tabular}

Table 15: An equality of variances test: a pre-test for a two-sample comparison of means test (paired), New York and London, 2020.

As previously, if the comparison of variance test result was significant (significant $(\mathrm{p}<0.05)$, a comparison of means test followed with the Welch's correction for unequal variances, whereas if the variance quotient was not significant $(\mathrm{p}>0.05)$, 
the equality of variances test was applied. The summary of the relevant results is presented in Table 16 and 17.

\begin{tabular}{|l|l|l|l|l|l|l|l|l|l|l|}
\hline \multirow{2}{*}{$\begin{array}{l}\text { Hypothesis 8: } \\
\text { Crime category (2019) }\end{array}$} & \multicolumn{3}{|c|}{ Statistics for NYC } & \multicolumn{2}{|c|}{ Statistics for London } & \multicolumn{3}{c|}{ Comparison of means test } \\
\cline { 2 - 11 } & & & Mean & SD & N & Mean & SD & t-stat & p-value & Final result \\
\hline H8: Murder (Homicide) & 4 & 23 & 2 & 4 & 15 & 2 & -3.00 & 0.0119 & $\begin{array}{l}\text { significant } \\
(\mathrm{p}<0.05)\end{array}$ \\
\hline H8: Rape & 4 & 151 & 6 & 4 & 652 & 7 & 57.16 & 0.0000 & $\begin{array}{l}\text { significant } \\
(\mathrm{p}<0.05)\end{array}$ \\
\hline $\begin{array}{l}\text { H8: Robbery } \\
\text { Person) }\end{array}$ & 4 & 1011 & 65 & 4 & 3286 & 62 & 25.35 & 0.0000 & $\begin{array}{l}\text { significant } \\
(\mathrm{p}<0.05)\end{array}$ \\
\hline $\begin{array}{l}\text { H8: Burglary } \\
\text { H8: Grand Larceny (Theft) }\end{array}$ & 4 & 3447 & 136 & 4 & 21593 & 126 & 97.98 & 0.0000 & $\begin{array}{l}\text { significant } \\
(\mathrm{p}<0.05)\end{array}$ \\
\hline $\begin{array}{l}\text { H8: Grand Larceny Auto } \\
\text { (Vehicle Theft) }\end{array}$ & 4 & 378 & 34 & 4 & 2615 & 35 & 46.18 & 0.0000 & $\begin{array}{l}\text { significant } \\
(\mathrm{p}<0.05)\end{array}$ \\
\hline Total & 4 & 813 & 24 & 4 & 18540 & 344 & 47.27 & 0.0000 \\
\hline
\end{tabular}

Table 16: A two-sample comparison of means test (paired) with Welch's correction for unequal variances (if necessary and applicable), 2019.

\begin{tabular}{|l|l|l|l|l|l|l|l|l|l|l|}
\hline \multirow{2}{*}{$\begin{array}{l}\text { Hypothesis 8: } \\
\text { Crime category (2020) }\end{array}$} & \multicolumn{3}{|c|}{ Statistics for NYC } & \multicolumn{3}{|c|}{ Statistics for London } & \multicolumn{3}{c|}{ Comparison of means test } \\
\cline { 2 - 10 } & $\mathrm{N}$ & Mean & SD & N & Mean & SD & t-stat & $\mathrm{p}$-value & Final result \\
\hline H8: Murder (Homicide) & 4 & 32 & 4 & 4 & 10 & 1 & -5.72 & 0.0035 & $\begin{array}{l}\text { significant } \\
(\mathrm{p}<0.05)\end{array}$ \\
\hline H8: Rape & 4 & 95 & 10 & 4 & 534 & 38 & 11.16 & 0.0004 & $\begin{array}{l}\text { significant } \\
(\mathrm{p}<0.05)\end{array}$ \\
\hline H8: Robbery & 4 & 835 & 65 & 4 & 1709 & 358 & 2.40 & 0.0452 & $\begin{array}{l}\text { significant } \\
(\mathrm{p}<0.05)\end{array}$ \\
\hline $\begin{array}{l}\text { H8: Assault (Violence Against } \\
\text { Person) }\end{array}$ & 4 & 1551 & 167 & 4 & 17481 & 763 & 20.39 & 0.0001 & $\begin{array}{l}\text { significant } \\
(\mathrm{p}<0.05)\end{array}$ \\
\hline H8: Burglary & 4 & 1242 & 186 & 4 & 4308 & 376 & 7.31 & 0.0002 & $\begin{array}{l}\text { significant } \\
(\mathrm{p}<0.05)\end{array}$ \\
\hline H8: Grand Larceny (Theft) & 4 & 2142 & 227 & 4 & 10713 & 1678 & 5.06 & 0.0068 & $\begin{array}{l}\text { significant } \\
(\mathrm{p}<0.05)\end{array}$ \\
\hline $\begin{array}{l}\text { H8: Grand Larceny Auto } \\
\text { (Vehicle Theft) }\end{array}$ & 4 & 603 & 48 & 4 & 1882 & 128 & 9.36 & 0.0000 & $\begin{array}{l}\text { significant } \\
(\mathrm{p}<0.05)\end{array}$ \\
\hline Total & 28 & 928 & 144 & 28 & 5234 & 1184 & 3.61 & 0.0006 & $\begin{array}{l}\text { significant } \\
(\mathrm{p}<0.05)\end{array}$ \\
\hline
\end{tabular}

Table 17: A two-sample comparison of means test (paired) with Welch's correction for unequal variances (if necessary and applicable), 2020.

To sum up, in six categories, with the exception of homicide in London, the mean of crime in London was higher than that in New York City throughout the four months, in both 2019 and 2020 , whether under lockdown or not. The only exception is the category of murder, which in NYC was higher both in
2019 and 2020. Thus, Hypothesis 8 has been falsified. The crime trends in London and in New York City under the lockdown period are dissimilar. In other words, lockdown should not be perceived as an 'equalising' factor in the 
analysis of crime trends, and certainly cannot be treated as such in isolation from other variables.

\subsection{Hypotheses 9-16: Analysis and Findings}

Regression analysis was conducted on the crime data from New York City and London, accessed from the source listed in Footnote 6 (this was the source for Figure 17, and, together with the previously listed NYPD data, the source for Figures: $19,21,23,25,27,29$ and 31) and from the source listed in Footnote 7 (this was the source for Figure 34, and, together with the previously listed MET data the source for Figures: 36, 38, 40, 42, 44 and 46) from mid-March through June 2020. Although, as pointed out earlier, there had been concerns expressed by numerous statisticians and other scholars that the calculation methodology and presentation of the COVID cases may not have followed the expected standards, that is the case count was not rigorous and may have included cases counted twice or more times, the data for this experiment had been assumed as credible since they were published by the respective governmental bodies.

The analysis involved an OLS regression test. The independent variable in these tests was the number of COVID19 cases and the dependent variable was the number of crime incidents in each category. The tool applied for these tests was the OLS method, with four observations for each test, representing the number of months (Figure 18-31).

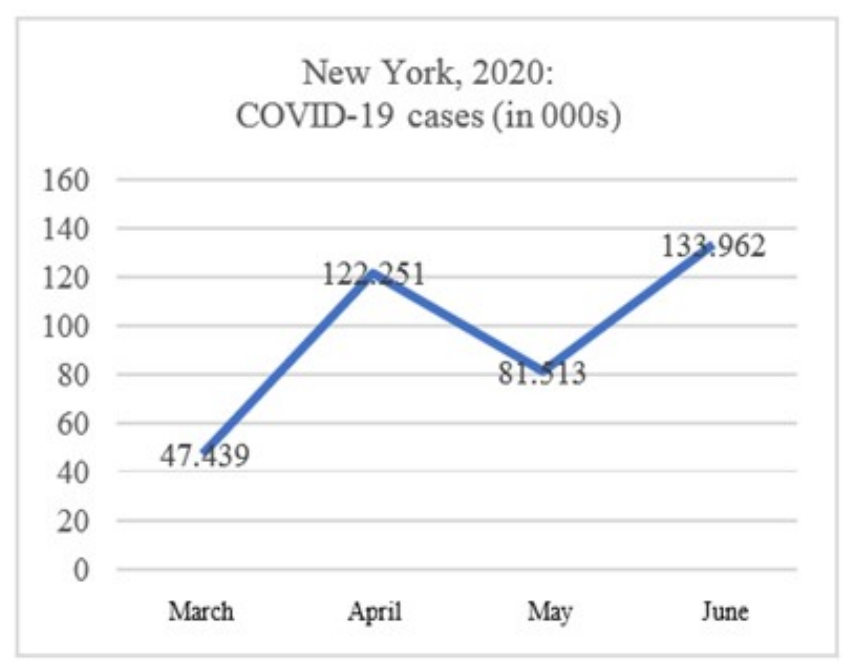

Figure 17: The total number of newly diagnosed COVID-19 cases (thousands) in New York between March-June 2020. 


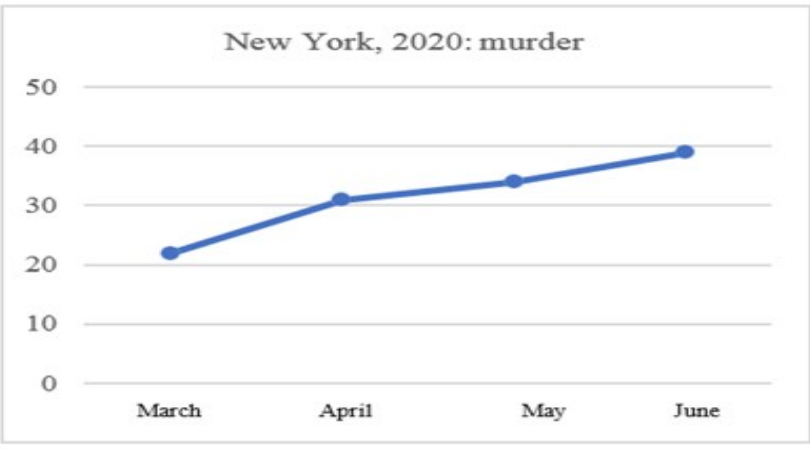

Figure 18: The number of murder incidents (absolute numbers) in New York between March-June 2020.

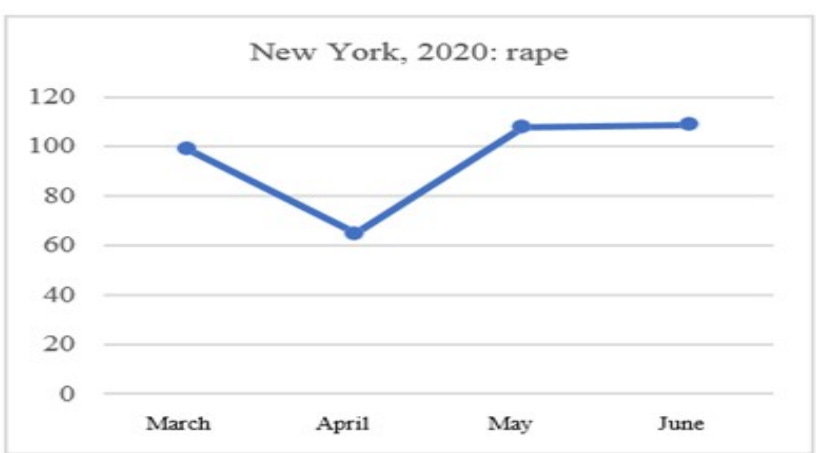

Figure 20: The number of rape incidents (absolute numbers) in New York between March-June, 2020.

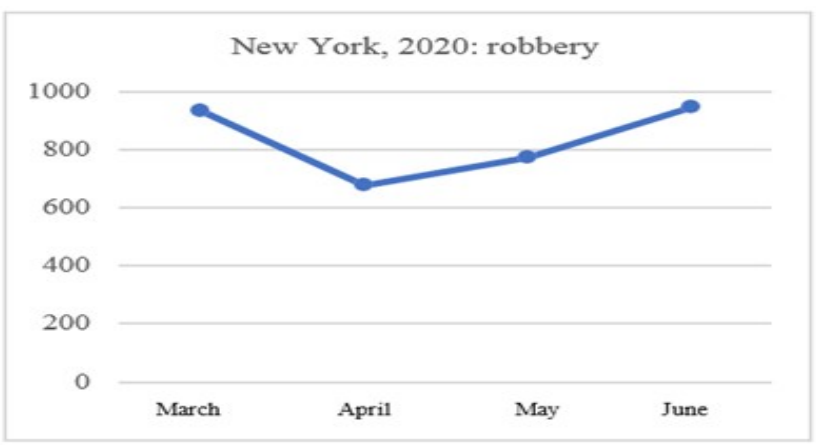

Figure 22: The number of robbery incidents (absolute numbers) in New York between March-June, 2020.

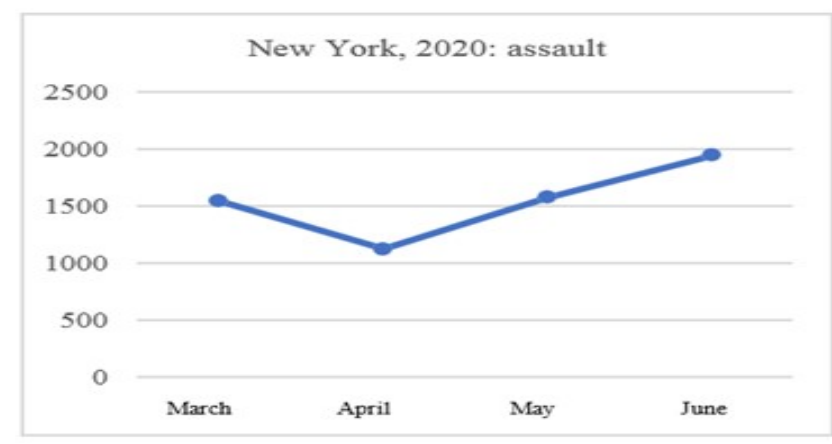

Figure 24: The number of assault incidents (absolute numbers) in New York between March-June, 2020.

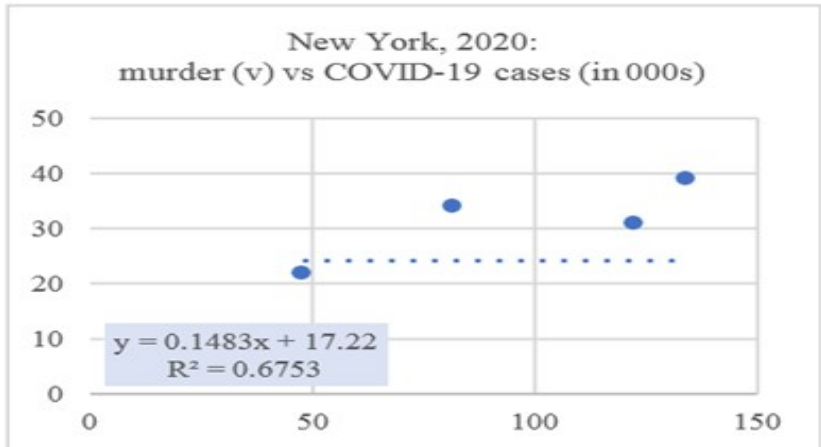

Figure 19: COVID-19 cases versus the number of murder incidents in New York between March-June, 2020.

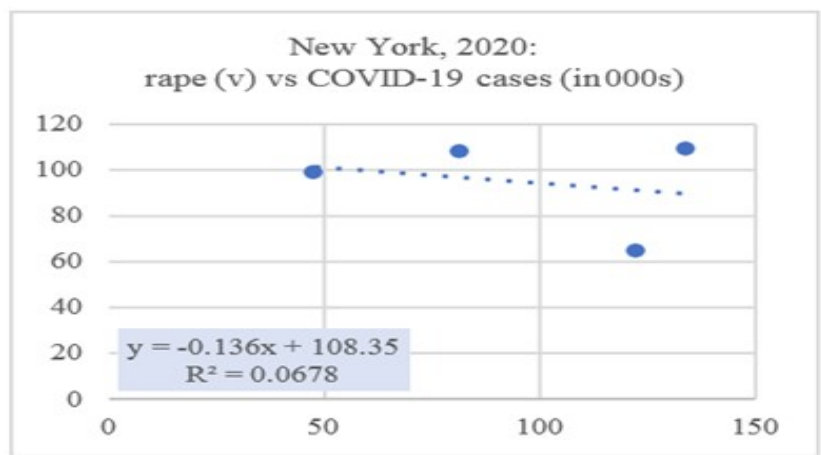

Figure 21: COVID-19 cases versus the number of rape incidents in New York between March-Jun, 2020.

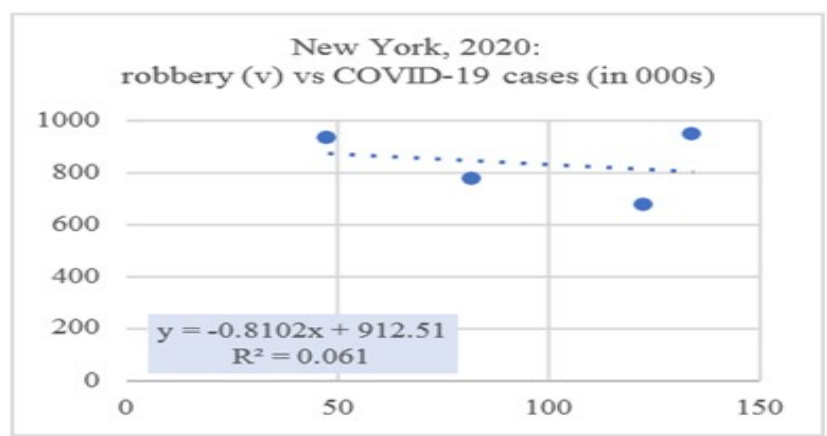

Figure 23: COVID-19 cases versus the number of robbery incidents in New York between March-June, 2020.

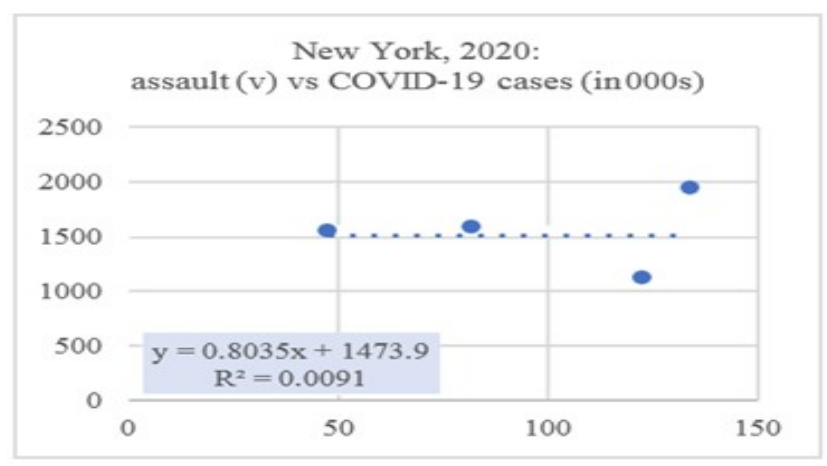

Figure 25: COVID-19 cases versus the number of assault incidents in New York between March-June, 2020. 


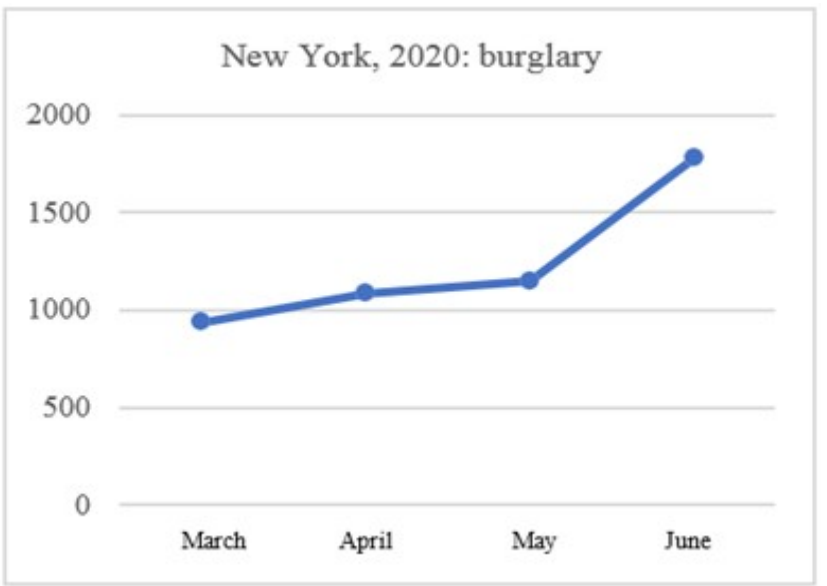

Figure 26: The number of burglary incidents (absolute numbers) in New York between March-June, 2020.

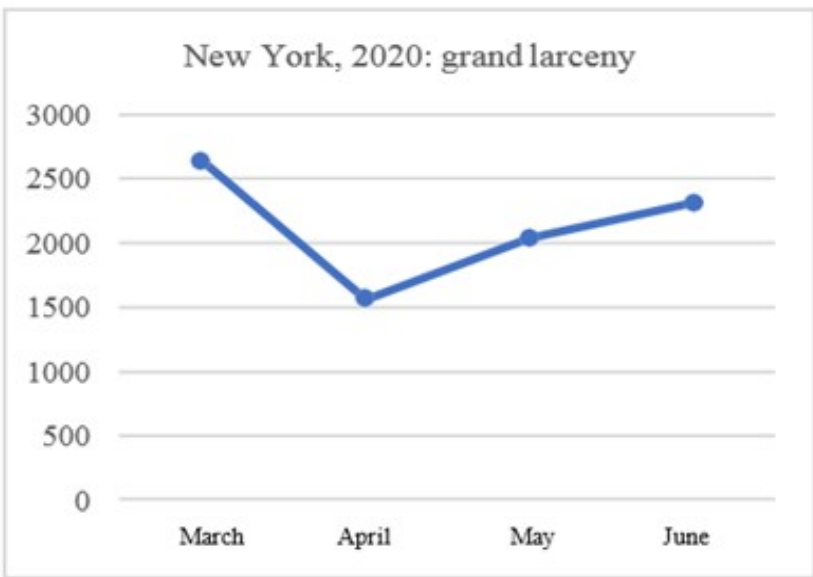

Figure 28: The number of grand lareny incidents (absolute numbers) in New York between March-June, 2020.

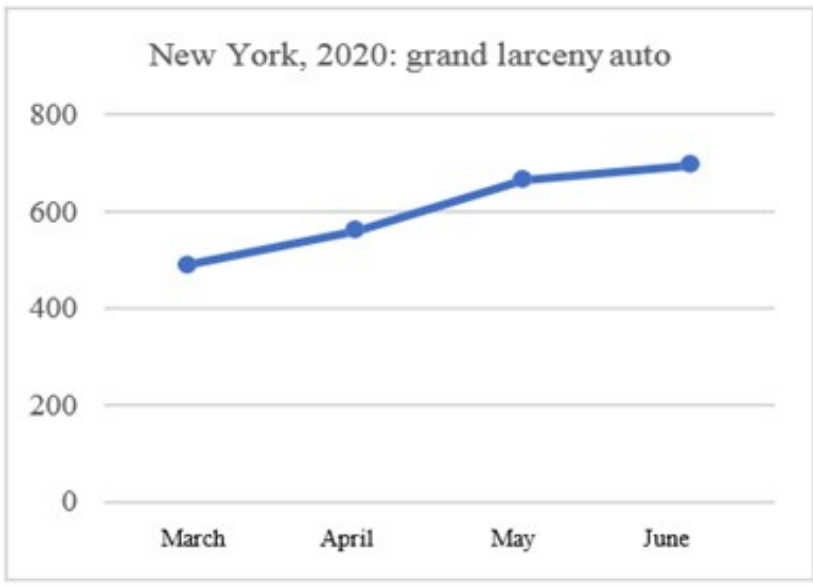

Figure 30: The number of grand larceny auto incidents (absolute numbers) in New York between March-June, 2020.

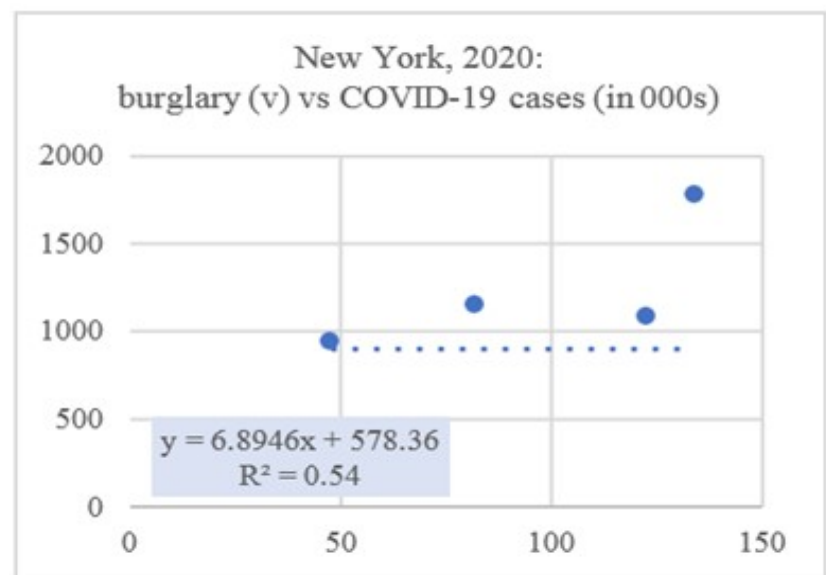

Figure 27: COVID-19 cases versus the number of burglary incidents in New York between March-June, 2020.

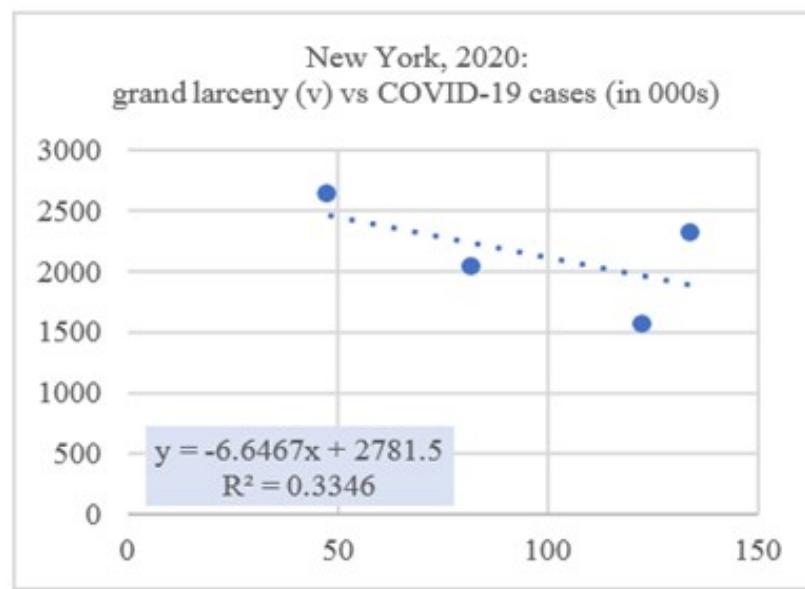

Figure 29: COVID-19 cases versus the number of grand larceny incidents in New York between March-June, 2020.

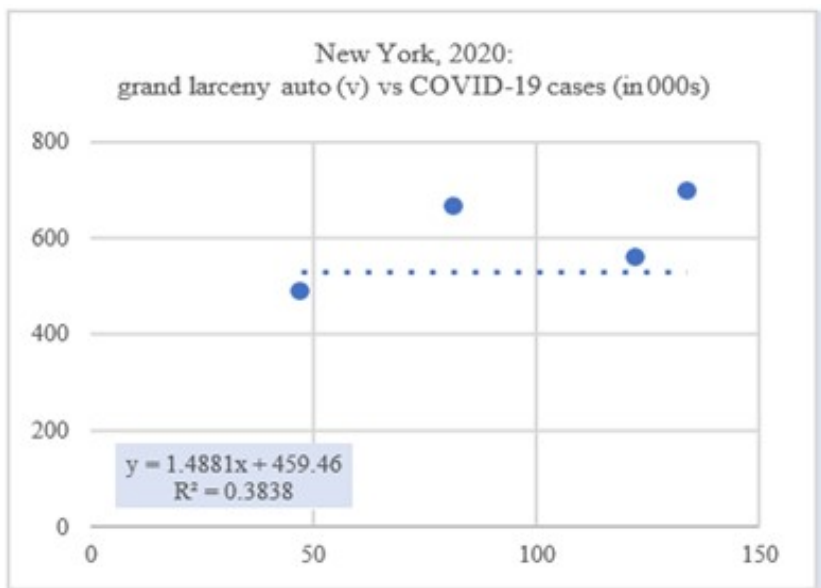

Figure 31: COVID-19 cases versus the number of grand larceny auto incidents in New York between March-June, 2020. 


\begin{tabular}{|c|c|c|c|c|c|c|c|}
\hline $\begin{array}{c}\text { Dependent } \\
\text { variable } \\
(y)\end{array}$ & $\begin{array}{c}\text { Independent } \\
\text { variable }(x)\end{array}$ & Coefficient & $\begin{array}{l}\text { Std. } \\
\text { error }\end{array}$ & t-stat & p-value & R-sq & $\begin{array}{c}\text { Model } \\
\text { equation (cases } \\
\text { in 000s) }\end{array}$ \\
\hline \multirow{2}{*}{ Murder } & COVID-19 cases & 0.00015 & 0.00007 & 2.04 & 0.178 & \multirow[b]{2}{*}{0.6753} & \multirow[b]{2}{*}{$y=17.2+0.148 x$} \\
\hline & (intercept) & 17.22 & 7.43 & 2.32 & 0.146 & & \\
\hline \multirow[b]{2}{*}{ Rape } & COVID-19 cases & -0.00014 & 0.00036 & -0.38 & 0.740 & \multirow[b]{2}{*}{0.0678} & \multirow[b]{2}{*}{$y=108-0.136 x$} \\
\hline & (intercept) & 108.35 & 36.43 & 2.97 & 0.097 & & \\
\hline \multirow{2}{*}{ Robbery } & COVID-19 cases & -0.00081 & 0.00225 & -0.36 & 0.753 & \multirow{2}{*}{0.0610} & \multirow[b]{2}{*}{$y=913-0.810 x$} \\
\hline & (intercept) & 912.51 & 229.81 & 3.97 & 0.058 & & \\
\hline \multirow[b]{2}{*}{ Assault } & COVID-19 cases & 0.00080 & 0.00594 & 0.14 & 0.905 & \multirow[b]{2}{*}{0.0091} & \multirow[b]{2}{*}{$y=1474+0.804 x$} \\
\hline & (intercept) & 1473.88 & 607.56 & 2.43 & 0.136 & & \\
\hline \multirow[b]{2}{*}{ Burglary } & COVID-19 cases & 0.00689 & 0.00450 & 1.53 & 0.265 & \multirow[b]{2}{*}{0.5400} & \multirow[b]{2}{*}{$y=578+6.89 x$} \\
\hline & (intercept) & 578.36 & 459.87 & 1.26 & 0.335 & & \\
\hline \multirow[b]{2}{*}{ Grand Larceny } & COVID-19 cases & -0.00665 & 0.00663 & -1.00 & 0.422 & \multirow{2}{*}{0.3346} & \multirow[b]{2}{*}{$y=2782-6.65 x$} \\
\hline & (intercept) & 2781.52 & 677.35 & 4.11 & 0.054 & & \\
\hline \multirow{2}{*}{$\begin{array}{l}\text { Grand Larceny } \\
\text { Auto }\end{array}$} & COVID-19 cases & 0.00149 & 0.00133 & 1.12 & 0.381 & \multirow[b]{2}{*}{0.3838} & \multirow[b]{2}{*}{$y=459+1.49 x$} \\
\hline & (intercept) & 459.46 & 136.29 & 3.37 & 0.078 & & \\
\hline
\end{tabular}

Table 18: Crime incidents regressed on COVID-19 cases, OLS using four observations, New York, March, April, May, June, 2020.

The results from the OLS calculations applied to New York are presented in the Table 18. There followed an identical analysis for the data from London. The results, as applied to London, are presented in Table 19. The individual and comparative results, for both cities, are discussed after the presentation of the graphic and numerical findings.

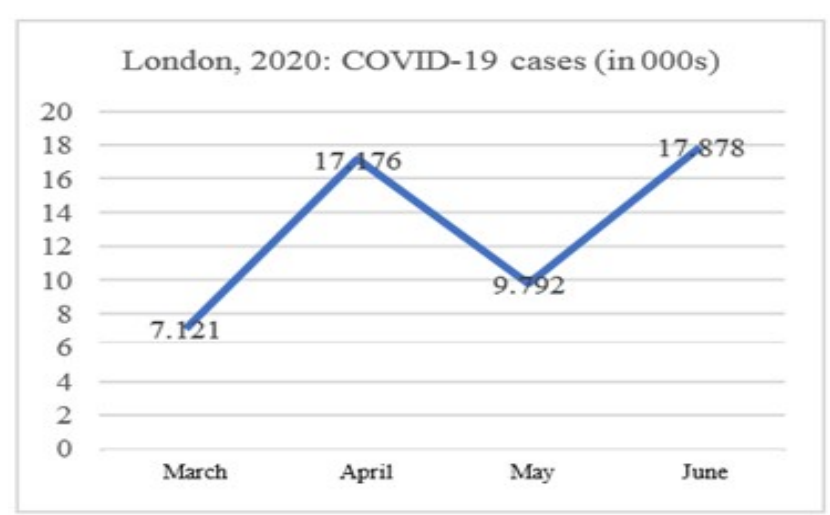

Figure 32: The total number of newly diagnosed COVID-19 cases (thousands) in London between March-June 2020. 


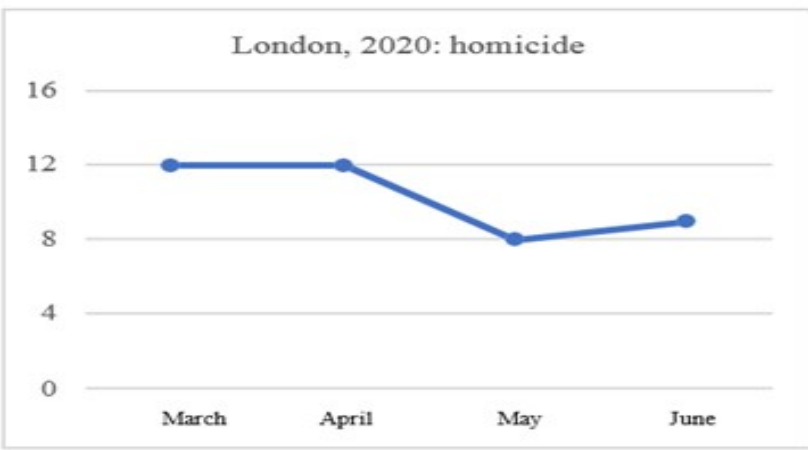

Figure 33: The number of homicide incidents (absolute numbers) in London between March-June, 2020.

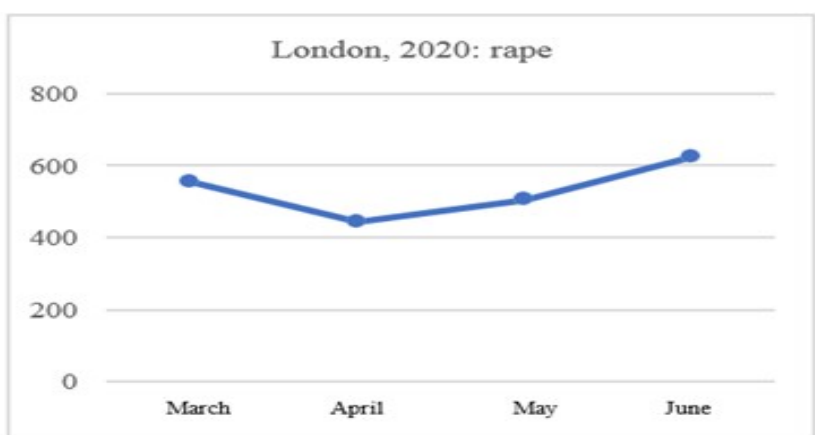

Figure 35: The number of rape incidents (absolute numbers) in London between March-June, 2020.

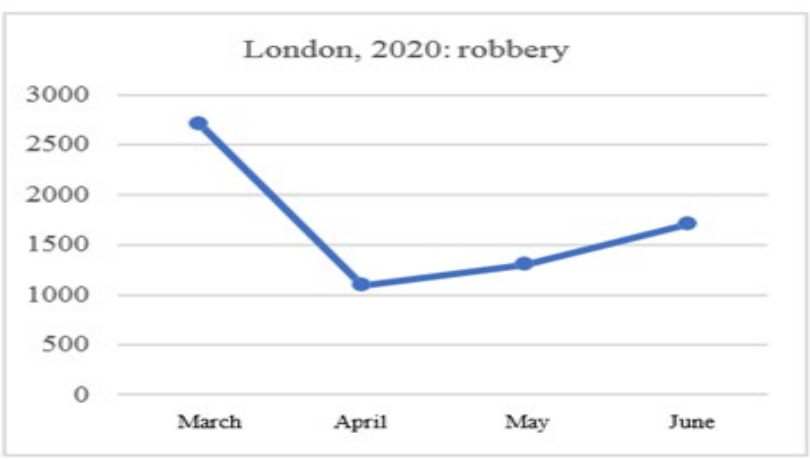

Figure 37: The number of robbery incidents (absolute numbers) in London between March-June, 2020.

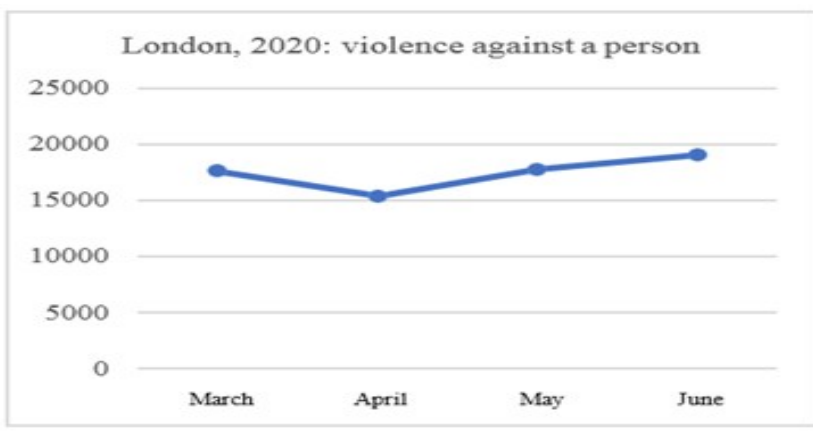

Figure 39: The number of violence against person incidents (absolute numbers) in London between March-June, 2020.

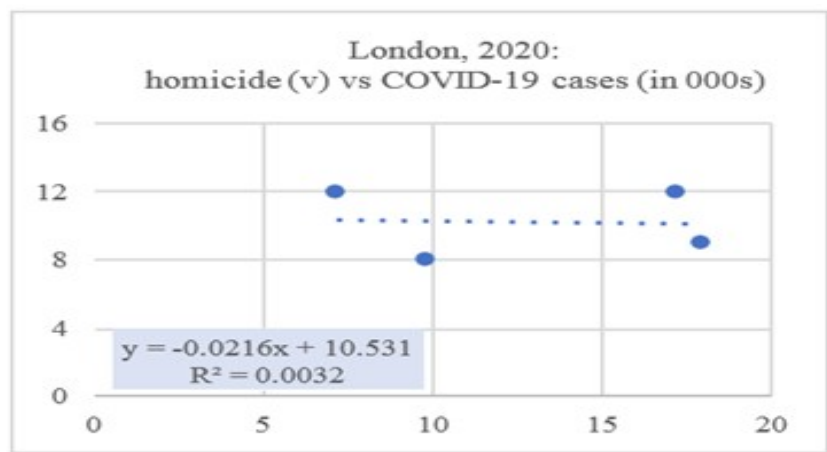

Figure 34: COVID-19 cases versus the number of homicide incidents in London between March-June, 2020.

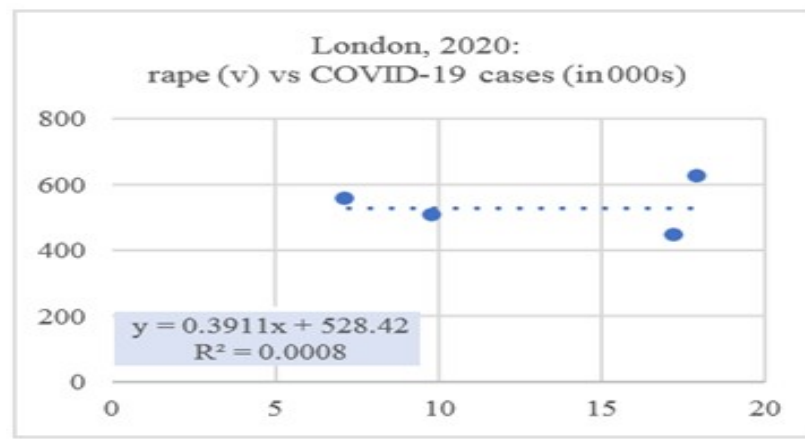

Figure 36: COVID-19 cases versus the number of rape incidents in London between March-June, 2020.

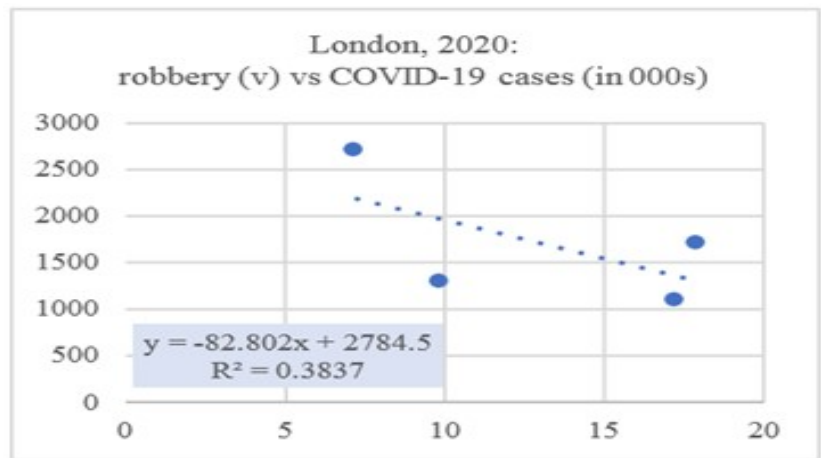

Figure 38: COVID-19 cases versus the number of robbery incidents in London between March-June, 2020.

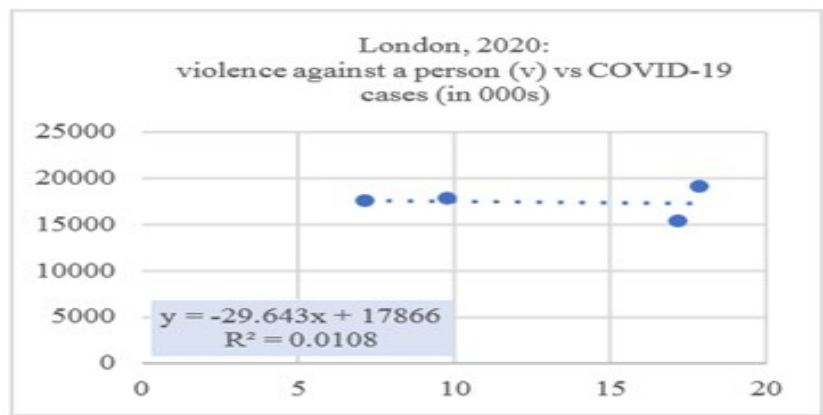

Figure 40: COVID-19 cases versus the number of violence against person incidents in London between March-June, 2020 . 


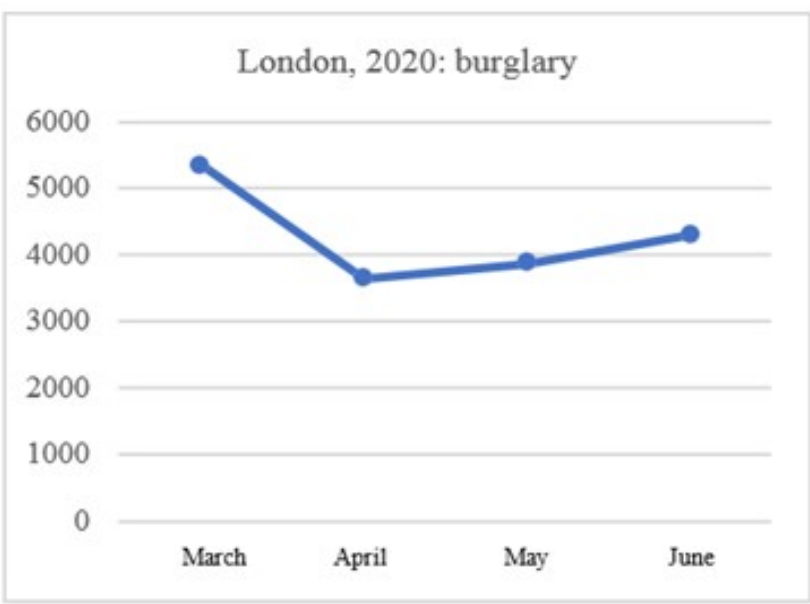

Figure 41: The number of burglary incidents (absolute numbers) in London between March-June, 2020.

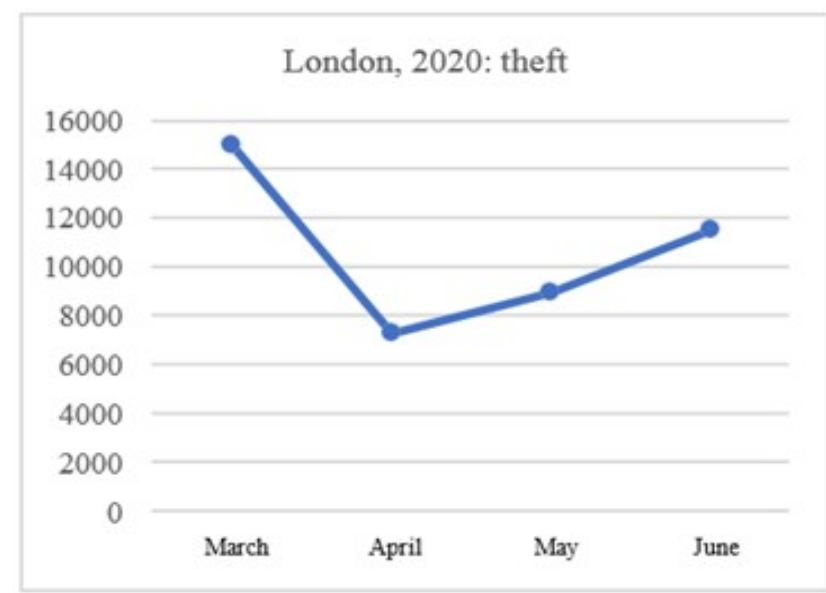

Figure 43: The number of theft incidents (absolute numbers) in London between March-June, 2020.

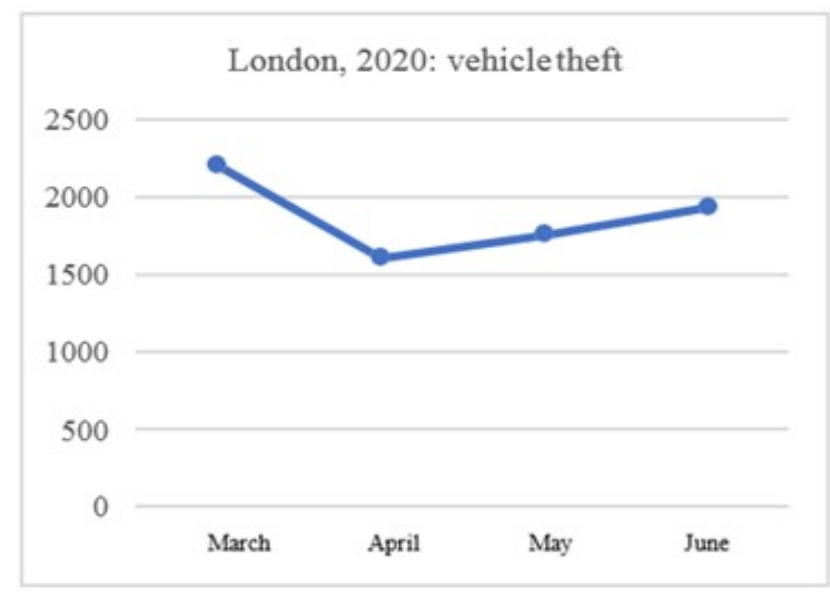

Figure 45: The number of vehicle theft incidents (absolute numbers) in London between March-June, 2020.

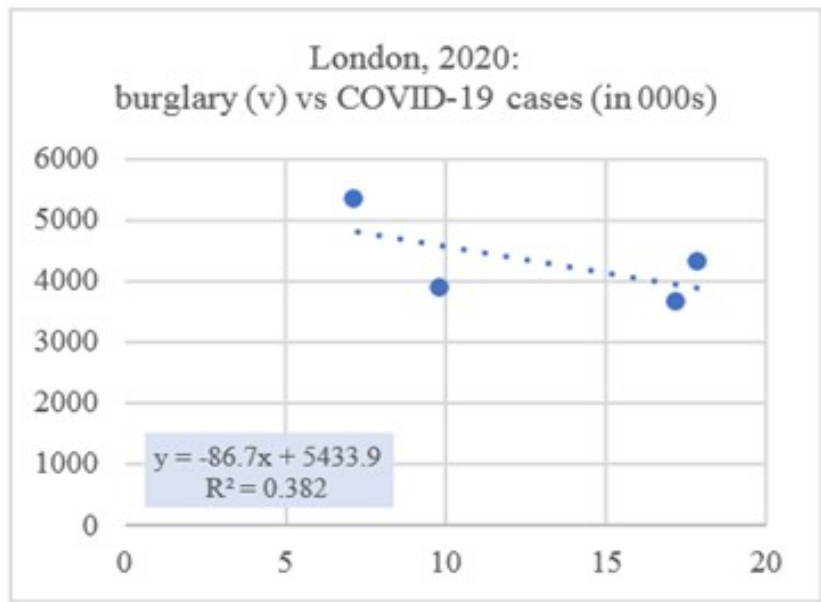

Figure 42: COVID-19 cases versus the number of burglary incidents in London between March-June, 2020.

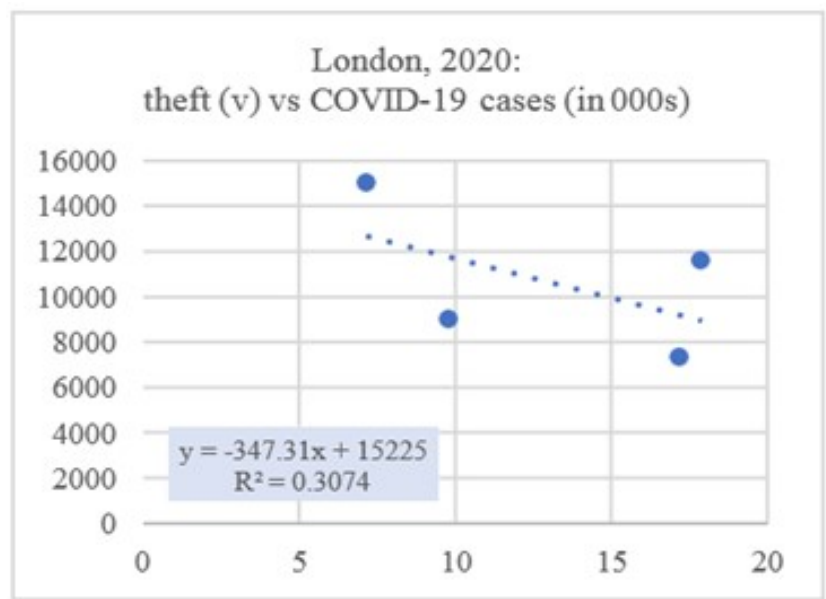

Figure 44: COVID-19 cases versus the number of theft incidents in London between March-June, 2020.

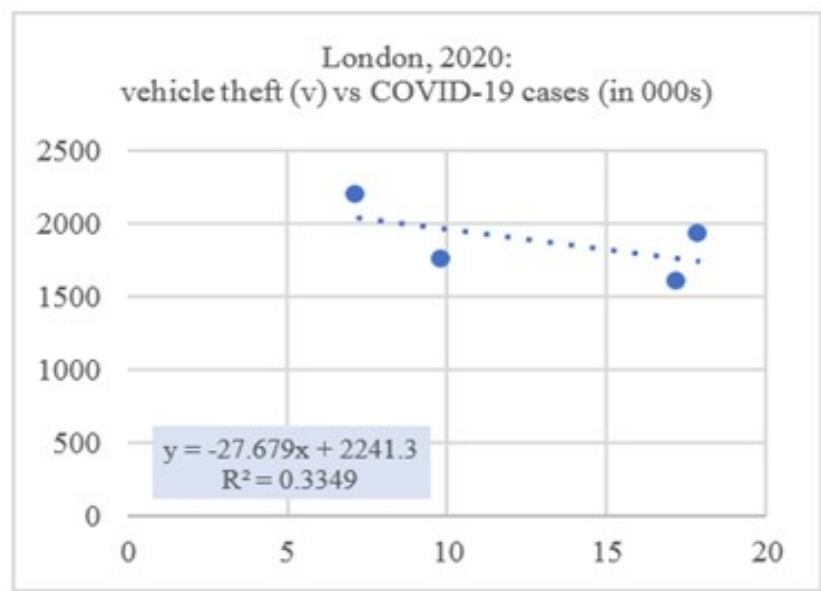

Figure 46: COVID-19 cases versus the number of vehicle theft incidents in London between March-June, 2020. 
The OLS results are presented in Table 19.

\begin{tabular}{|c|c|c|c|c|c|c|c|}
\hline $\begin{array}{c}\text { Dependent } \\
\text { variable } \\
(y)\end{array}$ & $\begin{array}{l}\text { Independent } \\
\text { variable }(x)\end{array}$ & Coefficient & $\begin{array}{l}\text { Std. } \\
\text { error }\end{array}$ & t-stat & p-value & R-sq & $\begin{array}{c}\text { Model } \\
\text { equation (cases } \\
\text { in } 000 \text { s) } \\
\end{array}$ \\
\hline \multirow{2}{*}{ Homicide } & COVID-19 cases & -0.00002 & 0.00027 & -0.08 & 0.944 & \multirow{2}{*}{0.0032} & \multirow{2}{*}{$y=10.5-0.0216 x$} \\
\hline & (intercept) & 10.53 & 3.75 & 2.81 & 0.107 & & \\
\hline \multirow{2}{*}{ Rape } & COVID-19 cases & 0.00039 & 0.01000 & 0.04 & 0.972 & \multirow{2}{*}{0.0008} & \multirow{2}{*}{$y=528+0.391 x$} \\
\hline & (intercept) & 528.42 & 137.98 & 3.83 & 0.062 & & \\
\hline \multirow{2}{*}{ Robbery } & COVID-19 cases & -0.08280 & 0.07420 & -1.12 & 0.381 & \multirow{2}{*}{0.3837} & \multirow{2}{*}{$y=2785-82.8 x$} \\
\hline & (intercept) & 2784.50 & 1023.56 & 2.72 & 0.113 & & \\
\hline \multirow{2}{*}{$\begin{array}{l}\text { Violence } \\
\text { Against Person }\end{array}$} & COVID-19 cases & -0.02964 & 0.20035 & -0.15 & 0.896 & \multirow{2}{*}{0.0108} & \multirow{2}{*}{$y=17866-29.6 x$} \\
\hline & (intercept) & 17865.86 & 2763.92 & 6.46 & 0.023 & & \\
\hline \multirow{2}{*}{ Burglary } & COVID-19 cases & -0.08670 & 0.07799 & -1.11 & 0.382 & \multirow{2}{*}{0.3820} & \multirow{2}{*}{$y=5434-86.7 x$} \\
\hline & (intercept) & 5433.89 & 1075.82 & 5.05 & 0.037 & & \\
\hline \multirow{2}{*}{ Theft } & COVID-19 cases & -0.34731 & 0.36865 & -0.94 & 0.446 & \multirow{2}{*}{0.3074} & \multirow{2}{*}{$y=15225-347 x$} \\
\hline & (intercept) & 15224.91 & 5085.54 & 2.99 & 0.096 & & \\
\hline \multirow{2}{*}{ Vehicle Theft } & COVID-19 cases & -0.02768 & 0.02758 & -1.00 & 0.421 & \multirow{2}{*}{0.3349} & \multirow{2}{*}{$y=2241-27.7 x$} \\
\hline & (intercept) & 2241.35 & 380.49 & 5.89 & 0.028 & & \\
\hline
\end{tabular}

Table 19: Crime incidents regressed on COVID-19 cases, OLS using four observations, London, March, April, May, June, 2020.

In view of the p-values, none of the 14 OLS models turned out to be statistically significant. The smallest $\mathrm{p}$-value is that for murder in New York City (0.178).

New York City: The analysis of the models demonstrates that the function coefficient is negative for: rape, robbery and grand larceny. This indicates a negative correlation between the variables; as the number of COVID-19 cases grows, the number of crime incidents in the corresponding crime category drops off. The function coefficient for the other four crime categories is positive, which means that as the number of COVID cases grows, the number of crime incidents in the categories under scrutiny also grows.

London: The analysis of the models demonstrates that the function coefficient is negative for: homicide, violence against a person, burglary, robbery, theft and vehicle theft. The inference therefore is that there is a negative correlation between the number of COVID case and the number of crime incidents in those categories. This means that as the number of COVID cases grows, the number of crime incidents in the categories under study drops off. Only in the case of rape is there a positive correlation, that is as the number of COVID cases grows, the number of rape incidents in London goes up.

If it is accepted that there indeed is a correlation between the number of COVID-19 cases and crime reduction (Hypotheses 9-15), it can be concluded that three of these hypotheses have been validated in New York City: hypothesis 10 (rape), 11 (robbery) and 14 (grand larceny). In the case of London, six of the hypotheses have been validated: 9 (homicide), 11 (robbery), 12 (violence against a person), 13 (burglary), 14 (theft) and 15 (vehicle theft). These results are consistent with the Hypotheses 1-7 validation process.

\section{DISCUSSION \\ CONCLUSIONS}

\subsection{Discussion}

As exemplified by the results of this research study, the introduction of lockdown can be deemed as to produce a reduction in certain crime categories in both cities, with an overall $15 \%$ and $31 \%$ drop in New York City and London, respectively. The initial drop off in crime was more pronounced and sustained in London. The relative change in each month there was respectively: 4.7 times, 1.5 times, 1.7 times and 4.3 times larger in London as compared to NYC. However, several findings seem to distort this seemingly unambiguous picture. Murder, robbery, assault, burglary, and grand larceny auto did not experience a drop in NYC. Neither did violence against a person in London. The incidence of murder (homicide) should probably be excluded from the conclusions, as there are few observations (more for NYC) and conclusions in this regard may be distorted. On the other hand, the fact that 33 more persons in 2020 fell victim to murder in NYC under the Spring Lockdown than in the same period a year earlier, should certainly provoke further investigation. 
As already stated, the year-to-year four-month relative comparison based on the results presented in Table 4 indicates that the crime trajectory in London during the Spring 2020 Lockdown indeed occurred in accordance with the theoretical foundations put forward by the RAT and subsequent contributors, even given the relatively short period of observation. However, the relative changes to crime in NYC proved to be contrary to the expectations, since the initial fall in crime occurred distinctly only in the category of rape, assault and grand larceny. Robbery incidents were on the rise in March although since April they followed the expectations. However, the hypothesised decline in burglary and grand larceny auto - anticipated to fall due to the (expected) increased guardianship, intensified by the stay-home orders not only did not go down but, in fact, increased by almost $89 \%$. As already stated, such a change could be seen as contradictory to the long-established assumptions, even despite the short period of observation. The sources of this detrimental change would therefore need to be analysed in conjunction with the lockdown and other hypothesised variables. The lockdown variable itself would need to be analysed and deconstructed thoroughly if credible answers were to be found. Given the brevity of the period of observation, the analysis may be subject to multi-angled criticism, since it seems to stay in contrast with some theoretical foundations as well certain findings in contemporary literature.

The results drawn from the inferential statistics tests allow for the rejection of the null hypotheses 2 and 6 (rape and grand larceny) for NYC, and the null hypotheses 1, 2, 3, 5, 6 and 7 (homicide, rape, robbery, burglary, theft and vehicle theft) for London. The results of these tests allow to support the conclusion that lockdown - in accordance with the expectations - did act as a possible deterrent as far as some categories of crime are concerned. However, there are few similarities between the cities in this aspect. The results of the statistical inference tests indicate that the dispersion of crime between the respective years and between the cities do not allow to draw a conclusion that the crime processes showed similarity in the two cities. It is therefore unjustified to ascribe the changes in crime trajectories in the respective cities in the four months under investigation to the lockdown itself, although - as already pointed out - the course of crime development in London may tentatively indicate an initial negative correlation (as lockdown is introduced and tightened, the number of the selected crime incidents falls).

The additional correlation tests which attempted to establish a relationship between COVID-19 and crime, where COVID-19 cases were assumed to be a proxy variable, seem to confirm those initial conclusions although there are several limitations regarding the correlation analysis.

\subsection{Limitations of the Study}

One of the most important limitations in this study is the number of observations. Both data sets presented the data in monthly intervals only. This made the data presentation and testing overly simplistic. It was not possible, for example, to correlate the exact dates of the lockdown introduction in London (23 March 2020) and New York City (16 March 2020) with the corresponding week in the crime data. Similarly, it was not possible to correlate the date on which lockdown started to be lifted: 13 June 2020 in London; 8 June 2020 in NYC and 15 May 2020 in the state of New York. The sparse frequency of the data did not allow for more sensitive and reliable testing of the RAT. Daily data would allow for a more precise test, such as the SARIMA test, used by Ashby [9].

Another issue is the overt generalisation used to establish the variable 'lockdown'. In reality, this variable should be deconstructed into several partial variables, such as 'stayhome' orders, 'work from home' recommendations, 'fill in public transport to a reduced capacity' orders, etc. A question remains whether these variables could be quantified. Nevertheless, building a model which could accommodate such a sophisticated break-down is beyond the feasibility of this study.

One more limitation of this study is the fact that it only presents a limited number of statistical results, derived from processing a selected number of publicly accessible sources. It is possible that other research tools as well as data sets could enrich the propositions put forward in this study, for example a comparative study focused on the 'strict lockdown' as opposed to 'soft lockdown/no lockdown' countries and their crime data from 2020. Another proposition could be a case study, focused on Sweden alone, as a country with virtually no or few Spring Lockdown procedures or, finally, a possible comparison of Sweden and another country, for instance, The Czech Republic (these two countries are similar in the population size but reacted very differently to COVID-19) in regard to crime levels in Spring 2020. It could also be interesting to compare the crime data from Sweden with those of Germany and the UK, as representing two countries with considerably strict lockdown measures. Again, such a research study is beyond the framework of this paper but might be suggested as a possible research avenue.

\subsection{Concluding Remarks}

The mixed findings which emerged from this study follow - to some degree - the body of the recent literature on the relationship between lockdown and crime change. The authors, whose contribution to criminology was summarised in Table 1, also presented mixed results. Most of those papers documented the drop off in the crime rate after the introduction of lockdown, although not universally. In the case of London, the theoretical foundation, that is, the proposition that an increased level of guardianship which serves as a protective element and reduces the number of burglaries, was confirmed by the empirical evidence almost to the letter but several of the results observed in New York City stay in contradiction to the RAT.

There was no homogeneity in proving the overall 'beneficial', that is the crime reducing effect of lockdown. The findings presented in this paper cannot be perceived as unconditionally 
supporting such conclusions albeit they are drawn from a sample of two cities only and cannot be viewed as representative.

The similarity of the sample statistical properties between the years 2019 and 2020 (with the exception of the aggregated total crime count in NYC) and the dissimilarity of the crime processes between the cities demonstrated by the comparison of means tests allows to infer that the criminal patterns remained similar to the pre-lockdown conditions and characteristics. It is true that there was a general drop off in crime incidents. However, it is impossible to speculate that the cost of law enforcement maintenance during those four months of the Spring Lockdown in 2020 must have decreased accordingly. If we take into consideration the fact that the number of calls for police service increased (Table 1) and the police servicing of the lockdown, that is quarantine checks, monitoring social distance restrictions, controlling the outlets that remained open etc. the costs of police operations during the period under study might have stayed similar or higher.

One of the quantifiably justified positive conclusions regarding London is that there were lives saved - as the number of homicide incidents decreased while rape offences occurred less frequently in both cities - but, sadly, violent crime, such as murder and robbery was on the rise in New York City consistently throughout the period under study. It is possible the protests and the ensuing commercial outlets break-ins and looting were partly responsible for the growth in crime in NYC in the latter part of the Spring Lockdown.

Therefore, it seems that the results of this study present a cautionary tale. Rather than adding to the evidence in favour of the grand criminal theories, they seem to support the argument by Stickle and Felson [13], discussed in the literature review, namely that the size and intensity of the lockdown and its subsequent impact on crime - otherwise known as the largest criminological experiment in history poses a challenge to criminologists in their quest to explain this unprecedented lockdown-provoked upheaval in crime trends. In consequence, the conclusions drawn from the comparative analysis of the crime trends in NYC and London allow to support one of the arguments presented by Stickle and Felson [13], that is that the changes in crime under lockdown are uneven spatially, chronologically and in the matter of category rather than unequivocally confirm the propositions of the RAT.

Perhaps the social, economic and civilisational changes which have permeated the world since the 1980s are presenting a new challenge which would allow enriching the RAT and the follow-ups to the theory. It would certainly seem that the

\begin{tabular}{|c|c|c|c|c|c|c|c|c|c|}
\hline \multirow{2}{*}{$\begin{array}{c}\text { NYC: } \\
\text { hypothesis number } \\
\text { \& crime category }\end{array}$} & \multicolumn{3}{|c|}{ Statistics for 2019} & \multicolumn{3}{|c|}{ Statistics for 2020} & \multicolumn{3}{|c|}{ Variance ratio test } \\
\hline & $\mathrm{N}$ & mean & $\mathrm{SD}$ & $\mathrm{N}$ & mean & $\mathrm{SD}$ & F-stat & p-value & final result \\
\hline H1: Murder & 4 & 23 & 2 & 4 & 32 & 4 & 2.2 & 0.2641 & not significant $(\mathrm{p}>0.05)$ \\
\hline H2: Rape & 4 & 151 & 6 & 4 & 95 & 10 & 3.2 & 0.1814 & not significant $(\mathrm{p}>0.05)$ \\
\hline
\end{tabular}

lockdown phenomenon cannot be perceived as a single 'breach' or be compared to a war or economic depression. It has affected every single aspect of life - distorting work, education, transport and communication, leisure and holiday patterns as well as negatively influencing mental health, and curtailing civil liberties and human rights, to mention some. Similarly, it has resulted in an asymmetric crime evolution. Its imprint should be analysed from every angle. No theory can comprehensively explain lockdown induced changes in crime volume and characteristics, as they are bringing along new challenges and costs. The phenomenon of lockdown and its consequences on crime development may require sophisticated tools and a large pool (drawn from different countries) of data which could be processed comparatively. Such a comparative analysis, conducted on a data set encompassing a year, could throw light on the more detailed, precise and verifiable effects of the lockdown on crime.

\subsection{Recommendations for Further Studies, Policy Makers and Law Enforcement}

The primary recommendation for the policy makers is to weigh the pros and cons of a lockdown very carefully. The recommendation for the law enforcement officers is to estimate the costs of a possible re-introduction of lockdown, particularly in view of the evidence from New York City. Policy makers and the law enforcement personnel are also recommended to consider and estimate the costs of maintaining lockdown, especially in view of the temporary character of the lockdown cost reducing effect.

There are several research directions which could be drawn upon this study, some of which have already been listed. It would be interesting to decompose the variable 'lockdown' and relate it with the reduction in the number of burglary incidents, based on the results from London. A cost-benefit assessment of maintaining lockdown vis-a-vis expected savings from the reduction in crime is another possibility. Finally, it is recommended that a more comprehensive comparative study should be carried out. It is advised, however, that large, detailed and reliable sources of crime data, which would present it at more frequent intervals, be accessed in such future endeavours.

\section{ACKNOWLEDGEMENT}

A valuable inspirational and analytical contribution to this paper has been the $2020 \mathrm{MSc}$ in Crime Science dissertation of Caroline Byczynski, conducted at University College London (UCL).

\section{APPENDIX}




\begin{tabular}{|l|l|l|l|l|l|l|l|l|l|}
\hline H3: Robbery & 4 & 1011 & 65 & 4 & 835 & 65 & 1.0 & 0.4985 & not significant $(\mathrm{p}>0.05)$ \\
\hline H4: Assault & 4 & 1902 & 83 & 4 & 1551 & 167 & 4.0 & 0.1411 & not significant $(\mathrm{p}>0.05)$ \\
\hline H5: Burglary & 4 & 813 & 24 & 4 & 1242 & 186 & 59.2 & 0.0036 & significant $(\mathrm{p}<0.05)$ \\
\hline H6: Grand Larceny & 4 & 3447 & 136 & 4 & 2142 & 227 & 2.8 & 0.2097 & not significant $(\mathrm{p}>0.05)$ \\
\hline H7: Grand Larceny Auto & 4 & 378 & 34 & 4 & 603 & 48 & 2.0 & 0.2960 & not significant $(\mathrm{p}>0.05)$ \\
\hline Total & 28 & 1089 & 215 & 28 & 928 & 144 & 2.2 & 0.0209 & significant $(\mathrm{p}<0.05)$ \\
\hline
\end{tabular}

Table A: Equality of variances test results as a pre-test for a two-sample comparison of means rest results, NYC, 2019 to 2020.

\begin{tabular}{|c|c|c|c|c|c|c|c|c|c|}
\hline London: & \multicolumn{3}{|c|}{ Statistics for 2019} & \multicolumn{3}{|c|}{ Statistics for 2020} & \multicolumn{3}{|c|}{ Variance ratio test } \\
\hline $\begin{array}{l}\text { hypothesis number } \\
\& \text { crime category }\end{array}$ & $\mathrm{N}$ & mean & SD & $\mathrm{N}$ & mean & SD & F-stat & $\mathrm{p}$-value & final result \\
\hline H1: Homicide & 4 & 15 & 2 & 4 & 10 & 1 & 2.6 & 0.2277 & not significant $(p>0.05)$ \\
\hline H2: Rape & 4 & 652 & 7 & 4 & 534 & 38 & 32.8 & 0.0085 & significant $(\mathrm{p}<0.05)$ \\
\hline H3: Robbery & 4 & 3286 & 62 & 4 & 1709 & 358 & 33.6 & 0.0083 & significant $(\mathrm{p}<0.05)$ \\
\hline H4: Violence Against Person & 4 & 18540 & 344 & 4 & 17481 & 763 & 4.9 & 0.1118 & not significant $(p>0.05)$ \\
\hline H5: Burglary & 4 & 6581 & 215 & 4 & 4308 & 376 & 3.1 & 0.1909 & not significant $(p>0.05)$ \\
\hline H6: Theft & 4 & 21593 & 126 & 4 & 10713 & 1678 & 177.3 & 0.0007 & significant $(\mathrm{p}<0.05)$ \\
\hline H7: Vehicle Theft & 4 & 2615 & 35 & 4 & 1882 & 128 & 13.7 & 0.0295 & significant $(\mathrm{p}<0.05)$ \\
\hline Total & 28 & 7612 & 1571 & 28 & 5234 & 1184 & 1.8 & 0.0741 & not significant $(p>0.05)$ \\
\hline
\end{tabular}

Table B: Equality of variances test results as a pre-test for a two-sample comparison of means rest results, NYC, 2019 to 2020.

\begin{tabular}{|l|l|l|l|l|l|l|l|l|l|}
\hline \multirow{2}{*}{$\begin{array}{c}\text { NYC: } \\
\begin{array}{c}\text { hypothesis number } \\
\text { \& crime category }\end{array}\end{array}$} & \multicolumn{3}{|c|}{ Statistics for 2019 } & \multicolumn{3}{c|}{ Statistics for 2020 } & \multicolumn{3}{c|}{ Comparison of means test } \\
\cline { 2 - 11 } & $\mathrm{N}$ & mean & SD & $\mathrm{N}$ & mean & SD & t-stat & p-value & final result \\
\hline H1: Murder & 4 & 23 & 2 & 4 & 32 & 4 & -1.92 & 0.0517 & not significant $(\mathrm{p}>0.05)$ \\
\hline H2: Rape & 4 & 151 & 6 & 4 & 95 & 10 & 4.71 & 0.0016 & significant $(\mathrm{p}<0.05)$ \\
\hline H3: Robbery & 4 & 1011 & 65 & 4 & 835 & 65 & 1.91 & 0.0520 & not significant $(\mathrm{p}>0.05)$ \\
\hline H4: Assault & 4 & 1902 & 83 & 4 & 1551 & 167 & 1.34 & 0.1139 & not significant $(\mathrm{p}>0.05)$ \\
\hline H5: Burglary & 4 & 813 & 24 & 4 & 1242 & 186 & -2.29 & 0.0308 & significant $(\mathrm{p}<0.05)$ \\
\hline H6: Grand Larceny & 4 & 3447 & 136 & 4 & 2142 & 227 & 4.93 & 0.0013 & significant $(\mathrm{p}<0.05)$ \\
\hline H7: Grand Larceny Auto & 4 & 378 & 34 & 4 & 603 & 48 & -3.85 & 0.0042 & significant $(\mathrm{p}<0.05)$ \\
\hline Total & 28 & 1089 & 215 & 28 & 928 & 144 & 0.62 & 0.2688 & not significant $(\mathrm{p}>0.05)$ \\
\hline
\end{tabular}

Table C: Two-sample comparison of means test (paired): version A (for equal variances), NYC, 2019 to 2020.

\begin{tabular}{|l|l|l|l|l|l|l|l|l|l|}
\hline \multirow{2}{*}{$\begin{array}{c}\text { London: } \\
\begin{array}{c}\text { hypothesis number } \\
\text { \& crime category }\end{array}\end{array}$} & \multicolumn{3}{|c|}{ Statistics for 2019 } & \multicolumn{3}{c|}{ Statistics for 2020 } & \multicolumn{3}{c|}{ Comparison of means test } \\
\cline { 2 - 12 } & $\mathrm{N}$ & mean & SD & N & mean & SD & t-stat & p-value & final result \\
\hline H1: Homicide & 4 & 15 & 2 & 4 & 10 & 1 & 2.18 & 0.0362 & significant $(\mathrm{p}<0.05)$ \\
\hline H2: Rape & 4 & 652 & 7 & 4 & 534 & 38 & 3.09 & 0.0107 & significant $(\mathrm{p}<0.05)$ \\
\hline H3: Robbery & 4 & 3286 & 62 & 4 & 1709 & 358 & 4.34 & 0.0024 & significant $(\mathrm{p}<0.05)$ \\
\hline H4: Violence Against Person & 4 & 18540 & 344 & 4 & 17481 & 763 & 1.27 & 0.1264 & not significant $(\mathrm{p}>0.05)$ \\
\hline H5: Burglary & 4 & 6581 & 215 & 4 & 4308 & 376 & 5.25 & 0.0010 & significant $(\mathrm{p}<0.05)$ \\
\hline H6: Theft & 4 & 21593 & 126 & 4 & 10713 & 1678 & 6.47 & 0.0003 & significant $(\mathrm{p}<0.05)$ \\
\hline H7: Vehicle Theft & 4 & 2615 & 35 & 4 & 1882 & 128 & 5.52 & 0.0007 & significant $(\mathrm{p}<0.05)$ \\
\hline Total & 28 & 7612 & 1571 & 28 & 5234 & 1184 & 1.21 & 0.1160 & not significant $(\mathrm{p}>0.05)$ \\
\hline
\end{tabular}

Table D: Two-sample comparison of means test (paired): version A (for equal variances), London, 2019 to 2020. 


\begin{tabular}{|l|l|l|l|l|l|l|l|l|l|}
\hline \multirow{2}{*}{$\begin{array}{c}\text { NYC: } \\
\text { hypothesis number } \\
\& \text { crime category }\end{array}$} & \multicolumn{3}{|c|}{ Statistics for 2019 } & \multicolumn{3}{c|}{ Statistics for 2020 } & \multicolumn{3}{c|}{ Comparison of means test } \\
\cline { 2 - 11 } & $\mathrm{N}$ & mean & SD & $\mathrm{N}$ & mean & SD & t-stat & p-value & final result \\
\hline H1: Murder & 4 & 23 & 2 & 4 & 32 & 4 & -1.92 & 0.0552 & not significant $(\mathrm{p}>0.05)$ \\
\hline H2: Rape & 4 & 151 & 6 & 4 & 95 & 10 & 4.71 & 0.0031 & significant $(\mathrm{p}<0.05)$ \\
\hline H3: Robbery & 4 & 1011 & 65 & 4 & 835 & 65 & 1.91 & 0.0520 & not significant $(\mathrm{p}>0.05)$ \\
\hline H4: Assault & 4 & 1902 & 83 & 4 & 1551 & 167 & 1.34 & 0.1221 & not significant $(\mathrm{p}>0.05)$ \\
\hline H5: Burglary & 4 & 813 & 24 & 4 & 1242 & 186 & -2.29 & 0.0514 & not significant $(\mathrm{p}>0.05)$ \\
\hline H6: Grand Larceny & 4 & 3447 & 136 & 4 & 2142 & 227 & 4.93 & 0.0023 & significant $(\mathrm{p}<0.05)$ \\
\hline H7: Grand Larceny Auto & 4 & 378 & 34 & 4 & 603 & 48 & -3.85 & 0.0052 & significant $(\mathrm{p}<0.05)$ \\
\hline Total & 28 & 1089 & 215 & 28 & 928 & 144 & 0.62 & 0.2689 & not significant $(\mathrm{p}>0.05)$ \\
\hline
\end{tabular}

Table E: Two sample comparison of means test (paired): version B (for unequal variances, i.e., with Welch's correction), NYC, 2019 to 2020.

\begin{tabular}{|l|l|l|l|l|l|l|l|l|l|}
\hline \multirow{2}{*}{$\begin{array}{c}\text { London: } \\
\begin{array}{c}\text { hypothesis number } \\
\text { \& crime category }\end{array}\end{array}$} & \multicolumn{3}{|c|}{ Statistics for 2019 } & \multicolumn{3}{c|}{ Statistics for 2020 } & \multicolumn{3}{c|}{ Comparison of means test } \\
\cline { 2 - 11 } & $\mathrm{N}$ & mean & SD & N & mean & SD & t-stat & p-value & final result \\
\hline H1: Homicide & 4 & 15 & 2 & 4 & 10 & 1 & 2.18 & 0.0406 & significant $(\mathrm{p}<0.05)$ \\
\hline H2: Rape & 4 & 652 & 7 & 4 & 534 & 38 & 3.09 & 0.0249 & significant $(\mathrm{p}<0.05)$ \\
\hline H3: Robbery & 4 & 3286 & 62 & 4 & 1709 & 358 & 4.34 & 0.0100 & significant $(\mathrm{p}<0.05)$ \\
\hline H4: Violence Against Person & 4 & 18540 & 344 & 4 & 17481 & 763 & 1.27 & 0.1359 & not significant $(\mathrm{p}>0.05)$ \\
\hline H5: Burglary & 4 & 6581 & 215 & 4 & 4308 & 376 & 5.25 & 0.0019 & significant $(\mathrm{p}<0.05)$ \\
\hline H6: Theft & 4 & 21593 & 126 & 4 & 10713 & 1678 & 6.47 & 0.0036 & significant $(\mathrm{p}<0.05)$ \\
\hline H7: Vehicle Theft & 4 & 2615 & 35 & 4 & 1882 & 128 & 5.52 & 0.0040 & significant $(\mathrm{p}<0.05)$ \\
\hline Total & 28 & 7612 & 1571 & 28 & 5234 & 1184 & 1.21 & 0.1162 & not significant $(\mathrm{p}>0.05)$ \\
\hline
\end{tabular}

Table F: Two-sample comparison of means test (paired): version B (for unequal variances, i.e., with Welch's correction), London, 2019 to 2020.

\begin{tabular}{|l|l|l|l|l|l|l|l|l|l|}
\hline \multicolumn{1}{|c|}{$\begin{array}{c}\text { Hypothesis 8: } \\
\text { crime category (2019) }\end{array}$} & \multicolumn{3}{|c|}{ Statistics for NYC } & \multicolumn{2}{c|}{ Statistics for LDN } & \multicolumn{4}{c|}{ Variance ratio test } \\
\cline { 2 - 12 } & $\mathrm{N}$ & Mean & SD & N & mean & SD & F-stat & p-value & final result \\
\hline H9: Murder (Homicide) & 4 & 23 & 2 & 4 & 15 & 2 & 2.1 & 0.2810 & not significant $(\mathrm{p}>0.05)$ \\
\hline H9: Rape & 4 & 151 & 6 & 4 & 652 & 7 & 1.3 & 0.4128 & not significant $(\mathrm{p}>0.05)$ \\
\hline H9: Robbery & 4 & 1011 & 65 & 4 & 3286 & 62 & 1.1 & 0.4672 & not significant $(\mathrm{p}>0.05)$ \\
\hline H9: Assault (Violence Against Person) & 4 & 1802 & 83 & 4 & 18540 & 344 & 17.1 & 0.0217 & significant $(\mathrm{p}<0.05)$ \\
\hline H9: Burglary & 4 & 813 & 24 & 4 & 6581 & 215 & 78.5 & 0.0024 & significant $(\mathrm{p}<0.05)$ \\
\hline H9: Grand Larceny (Theft) & 4 & 3447 & 136 & 4 & 21593 & 126 & 1.2 & 0.4528 & not significant $(\mathrm{p}>0.05)$ \\
\hline H9: Grand Larceny Auto (Vehicle Theft) & 4 & 378 & 34 & 4 & 2615 & 35 & 1.0 & 0.4864 & not significant $(\mathrm{p}>0.05)$ \\
\hline Total & 28 & 1089 & 215 & 28 & 7612 & 1571 & 53.2 & 0.0000 & significant $(\mathrm{p}<0.05)$ \\
\hline
\end{tabular}

Table G: Equality of variances test as a pre-test for two-sample comparison of means test (paired), NYC to London, 2019.

\begin{tabular}{|l|l|l|l|l|l|l|l|l|l|l|}
\hline \multirow{2}{*}{$\begin{array}{c}\text { Hypothesis 8: } \\
\text { crime category (2020) }\end{array}$} & \multicolumn{3}{|c|}{ Statistics for NYC } & \multicolumn{3}{c|}{ Statistics for LDN } & \multicolumn{4}{c|}{ Variance ratio test } \\
\cline { 2 - 12 } & N & mean & SD & N & mean & SD & F-stat & p-value & final result \\
\hline H9: Murder (Homicide) & 4 & 32 & 4 & 4 & 10 & 1 & 12.00 & 0.0354 & significant $(\mathrm{p}<0.05)$ \\
\hline H9: Rape & 4 & 95 & 10 & 4 & 534 & 38 & 13.46 & 0.0302 & significant $(\mathrm{p}<0.05)$ \\
\hline H9: Robbery & 4 & 835 & 65 & 4 & 1709 & 358 & 30.41 & 0.0096 & significant $(\mathrm{p}<0.05)$ \\
\hline
\end{tabular}




\begin{tabular}{|l|l|l|l|l|l|l|l|l|l|}
\hline H9: Assault (Violence Against Person) & 4 & 1551 & 167 & 4 & 17481 & 763 & 20.85 & 0.0164 & significant $(\mathrm{p}<0.05)$ \\
\hline H9: Burglary & 4 & 1242 & 186 & 4 & 4308 & 376 & 4.10 & 0.1385 & not significant $(\mathrm{p}>0.05)$ \\
\hline H9: Grand Larceny (Theft) & 4 & 2142 & 227 & 4 & 10713 & 1678 & 54.47 & 0.0041 & significant $(\mathrm{p}<0.05)$ \\
\hline H9: Grand Larceny Auto (Vehicle Theft) & 4 & 603 & 48 & 4 & 1882 & 128 & 7.26 & 0.0688 & not significant $(\mathrm{p}>0.05)$ \\
\hline Total & 28 & 928 & 144 & 28 & 5234 & 1184 & 67.36 & 0.0000 & significant $(\mathrm{p}<0.05)$ \\
\hline
\end{tabular}

Table H: Equality of variances test as a pre-test for a two-sample comparison of means test (paired), NYC to London, 2020.

\begin{tabular}{|c|c|c|c|c|c|c|c|c|c|}
\hline \multirow{2}{*}{$\begin{array}{l}\text { Hypothesis 8: } \\
\text { crime category (2019) }\end{array}$} & \multicolumn{3}{|c|}{ Statistics for NYC } & \multicolumn{3}{|c|}{ Statistics for LDN } & \multicolumn{3}{|c|}{ Comparison of means test } \\
\hline & $\mathrm{N}$ & mean & $\mathrm{SD}$ & $\mathrm{N}$ & mean & $\mathrm{SD}$ & t-stat & p-value & final result \\
\hline H9: Murder (Homicide) & 4 & 23 & 2 & 4 & 15 & 2 & -3.00 & 0.0119 & significant $(\mathrm{p}<0.05)$ \\
\hline H9: Rape & 4 & 151 & 6 & 4 & 652 & 7 & 57.16 & 0.0000 & significant $(\mathrm{p}<0.05)$ \\
\hline H9: Robbery & 4 & 1011 & 65 & 4 & 3286 & 62 & 25.35 & 0.0000 & significant $(\mathrm{p}<0.05)$ \\
\hline H9: Assault (Violence Against Person) & 4 & 1802 & 83 & 4 & 18540 & 344 & 47.27 & 0.0000 & significant $(\mathrm{p}<0.05)$ \\
\hline H9: Burglary & 4 & 813 & 24 & 4 & 6581 & 215 & 26.72 & 0.0000 & significant $(\mathrm{p}<0.05)$ \\
\hline H9: Grand Larceny (Theft) & 4 & 3447 & 136 & 4 & 21593 & 126 & 97.98 & 0.0000 & significant $(\mathrm{p}<0.05)$ \\
\hline H9: Grand Larceny Auto (Vehicle Theft) & 4 & 378 & 34 & 4 & 2615 & 35 & 46.18 & 0.0000 & significant $(\mathrm{p}<0.05)$ \\
\hline Total & 28 & 1089 & 215 & 28 & 7612 & 1571 & 4.11 & 0.0001 & significant $(\mathrm{p}<0.05)$ \\
\hline
\end{tabular}

Table I: Two-sample comparison of means, version A (for equal variances), NYC to London, 2019.

\begin{tabular}{|l|l|l|l|l|l|l|l|l|l|}
\hline \multirow{2}{*}{$\begin{array}{c}\text { Hypothesis 8: } \\
\text { crime category (2020) }\end{array}$} & \multicolumn{3}{|c|}{ Statistics for NYC } & \multicolumn{2}{c|}{ Statistics for LDN } & \multicolumn{3}{c|}{ Comparison of means test } \\
\cline { 2 - 12 } & $\mathrm{N}$ & mean & SD & N & mean & SD & t-stat & p-value & final result \\
\hline H9: Murder (Homicide) & 4 & 32 & 4 & 4 & 10 & 1 & -5.72 & 0.0006 & significant $(\mathrm{p}<0.05)$ \\
\hline H9: Rape & 4 & 95 & 10 & 4 & 534 & 38 & 11.16 & 0.0000 & significant $(\mathrm{p}<0.05)$ \\
\hline H9: Robbery & 4 & 835 & 65 & 4 & 1709 & 358 & 2.40 & 0.0265 & significant $(\mathrm{p}<0.05)$ \\
\hline H9: Assault (Violence Against Person) & 4 & 1551 & 167 & 4 & 17481 & 763 & 20.39 & 0.0000 & significant $(\mathrm{p}<0.05)$ \\
\hline H9: Burglary & 4 & 1242 & 186 & 4 & 4308 & 376 & 7.31 & 0.0002 & significant $(\mathrm{p}<0.05)$ \\
\hline H9: Grand Larceny (Theft) & 4 & 2142 & 227 & 4 & 10713 & 1678 & 5.06 & 0.0012 & significant $(\mathrm{p}<0.05)$ \\
\hline H9: Grand Larceny Auto (Vehicle Theft) & 4 & 603 & 48 & 4 & 1882 & 128 & 9.36 & 0.0000 & significant $(\mathrm{p}<0.05)$ \\
\hline Total & 28 & 928 & 144 & 28 & 5234 & 1184 & 3.61 & 0.0003 & significant $(\mathrm{p}<0.05)$ \\
\hline
\end{tabular}

Table J: Two sample comparison of means test, version A (for equal variances), NYC to London, 2020.

\begin{tabular}{|l|l|l|l|l|l|l|l|l|l|}
\hline \multicolumn{1}{|c|}{$\begin{array}{c}\text { Hypothesis 8: } \\
\text { crime category (2019) }\end{array}$} & \multicolumn{2}{|c|}{ Statistics for NYC } & \multicolumn{2}{c|}{ Statistics for LDN } & \multicolumn{3}{c|}{ Comparison of means test } \\
\cline { 2 - 13 } & $\mathrm{N}$ & mean & SD & N & mean & SD & t-stat & p-value & final result \\
\hline H9: Murder (Homicide) & 4 & 23 & 2 & 4 & 15 & 2 & -3.00 & 0.0138 & significant $(\mathrm{p}<0.05)$ \\
\hline H9: Rape & 4 & 151 & 6 & 4 & 652 & 7 & 57.16 & 0.0000 & significant $(\mathrm{p}<0.05)$ \\
\hline H9: Robbery & 4 & 1011 & 65 & 4 & 3286 & 62 & 25.35 & 0.0000 & significant $(\mathrm{p}<0.05)$ \\
\hline H9: Assault (Violence Against Person) & 4 & 1802 & 83 & 4 & 18540 & 344 & 47.27 & 0.0000 & significant $(\mathrm{p}<0.05)$ \\
\hline H9: Burglary & 4 & 813 & 24 & 4 & 6581 & 215 & 26.72 & 0.0000 & significant $(\mathrm{p}<0.05)$ \\
\hline H9: Grand Larceny (Theft) & 4 & 3447 & 136 & 4 & 21593 & 126 & 97.98 & 0.0000 & significant $(\mathrm{p}<0.05)$ \\
\hline H9: Grand Larceny Auto (Vehicle Theft) & 4 & 378 & 34 & 4 & 2615 & 35 & 46.18 & 0.0000 & significant $(\mathrm{p}<0.05)$ \\
\hline Total & 28 & 1089 & 215 & 28 & 7612 & 1571 & 4.11 & 0.0002 & significant $(\mathrm{p}<0.05)$ \\
\hline
\end{tabular}

Table K: Two-sample mean-comparison test (paired): version B (for unequal variances, i.e., with Welch's correction), NYC to London, 2019.

Hypothesis 8:
crime category (2020)

\begin{tabular}{|c|c|c|c|c|c|}
\hline \multicolumn{3}{|c|}{ Statistics for NYC } & \multicolumn{3}{|c|}{ Statistics for LDN } \\
\hline N & mean & SD & N & mean & SD \\
\hline
\end{tabular}

Comparison of means test

\begin{tabular}{l|l} 
t-stat & p-value
\end{tabular}

final result 


\begin{tabular}{|l|l|l|l|l|l|l|l|l|l|}
\hline H9: Murder (Homicide) & 4 & 32 & 4 & 4 & 10 & 1 & -5.72 & 0.0035 & significant $(\mathrm{p}<0.05)$ \\
\hline H9: Rape & 4 & 95 & 10 & 4 & 534 & 38 & 11.16 & 0.0004 & significant $(\mathrm{p}<0.05)$ \\
\hline H9: Robbery & 4 & 835 & 65 & 4 & 1709 & 358 & 2.40 & 0.0452 & significant $(\mathrm{p}<0.05)$ \\
\hline H9: Assault (Violence Against Person) & 4 & 1551 & 167 & 4 & 17481 & 763 & 20.39 & 0.0001 & significant $(\mathrm{p}<0.05)$ \\
\hline H9: Burglary & 4 & 1242 & 186 & 4 & 4308 & 376 & 7.31 & 0.0006 & significant $(\mathrm{p}<0.05)$ \\
\hline H9: Grand Larceny (Theft) & 4 & 2142 & 227 & 4 & 10713 & 1678 & 5.06 & 0.0068 & significant $(\mathrm{p}<0.05)$ \\
\hline H9: Grand Larceny Auto (Vehicle Theft) & 4 & 603 & 48 & 4 & 1882 & 128 & 9.36 & 0.0005 & significant $(\mathrm{p}<0.05)$ \\
\hline Total & 28 & 928 & 144 & 28 & 5234 & 1184 & 3.61 & 0.0006 & significant $(\mathrm{p}<0.05)$ \\
\hline
\end{tabular}

Table L: Two-sample mean-comparison test (paired): version B (for unequal variances, i.e., with Welch's correction), NYC to London, 2020.

\begin{tabular}{|l|l|l|l|l|l|l|l|l|l|}
\hline \multirow{2}{*}{$\begin{array}{c}\text { Hypothesis 8: } \\
\text { crime category (2019) }\end{array}$} & \multicolumn{3}{|c|}{ Statistics for NYC } & \multicolumn{3}{c|}{ Statistics for LDN } & \multicolumn{3}{c|}{ Comparison of means test } \\
\cline { 2 - 12 } & N & mean & SD & N & mean & SD & t-stat & p-value & final result \\
\hline H9: Murder (Homicide) & 4 & 23 & 2 & 4 & 15 & 2 & -3.00 & 0.0119 & significant $(\mathrm{p}<0.05)$ \\
\hline H9: Rape & 4 & 151 & 6 & 4 & 652 & 7 & 57.16 & 0.0000 & significant $(\mathrm{p}<0.05)$ \\
\hline H9: Robbery & 4 & 1011 & 65 & 4 & 3286 & 62 & 25.35 & 0.0000 & significant $(\mathrm{p}<0.05)$ \\
\hline H9: Assault (Violence Against Person) & 4 & 1802 & 83 & 4 & 18540 & 344 & 47.27 & 0.0000 & significant $(\mathrm{p}<0.05)$ \\
\hline H9: Burglary & 4 & 813 & 24 & 4 & 6581 & 215 & 26.72 & 0.0000 & significant $(\mathrm{p}<0.05)$ \\
\hline H9: Grand Larceny (Theft) & 4 & 3447 & 136 & 4 & 21593 & 126 & 97.98 & 0.0000 & significant $(\mathrm{p}<0.05)$ \\
\hline H9: Grand Larceny Auto (Vehicle Theft) & 4 & 378 & 34 & 4 & 2615 & 35 & 46.18 & 0.0000 & significant $(\mathrm{p}<0.05)$ \\
\hline Total & 28 & 1089 & 215 & 28 & 7612 & 1571 & 4.11 & 0.0002 & significant $(\mathrm{p}<0.05)$ \\
\hline
\end{tabular}

Table M: Two-sample comparison of means test (paired) with Welch's correction for unequal variances (if necessary), NYC to London, 2019.

\begin{tabular}{|l|l|l|l|l|l|l|l|l|l|}
\hline \multirow{2}{*}{$\begin{array}{c}\text { Hypothesis 8: } \\
\text { crime category (2020) }\end{array}$} & \multicolumn{3}{|c|}{ Statistics for NYC } & \multicolumn{3}{c|}{ Statistics for LDN } & \multicolumn{4}{c|}{ Comparison of means test } \\
\cline { 2 - 12 } & $\mathrm{N}$ & mean & SD & N & mean & SD & t-stat & p-value & final result \\
\hline H9: Murder (Homicide) & 4 & 32 & 4 & 4 & 10 & 1 & -5.72 & 0.0035 & significant $(\mathrm{p}<0.05)$ \\
\hline H9: Rape & 4 & 95 & 10 & 4 & 534 & 38 & 11.16 & 0.0004 & significant $(\mathrm{p}<0.05)$ \\
\hline H9: Robbery & 4 & 835 & 65 & 4 & 1709 & 358 & 2.40 & 0.0452 & significant $(\mathrm{p}<0.05)$ \\
\hline H9: Assault (Violence Against Person) & 4 & 1551 & 167 & 4 & 17481 & 763 & 20.39 & 0.0001 & significant $(\mathrm{p}<0.05)$ \\
\hline H9: Burglary & 4 & 1242 & 186 & 4 & 4308 & 376 & 7.31 & 0.0002 & significant $(\mathrm{p}<0.05)$ \\
\hline H9: Grand Larceny (Theft) & 4 & 2142 & 227 & 4 & 10713 & 1678 & 5.06 & 0.0068 & significant $(\mathrm{p}<0.05)$ \\
\hline H9: Grand Larceny Auto (Vehicle Theft) & 4 & 603 & 48 & 4 & 1882 & 128 & 9.36 & 0.0000 & significant $(\mathrm{p}<0.05)$ \\
\hline Total & 28 & 928 & 144 & 28 & 5234 & 1184 & 3.61 & 0.0006 & significant $(\mathrm{p}<0.05)$ \\
\hline
\end{tabular}

Table N: Two-sample comparison of means test (paired) with Welch's correction for unequal variances (if necessary), NYC to London, 2020.

\section{REFERENCES}

[1] MET. (2020) Crime data dashboard | The Met.

[2] GOV.UK. (2020) Full guidance on staying at home and away from others.

[3] GOV.UK. (2020) Guidance on social distancing for everyone in the UK.

[4] Sargent, J., \& Nice, A. (2020) Coronavirus lockdown rules in each part of the UK, Institute for Government.

[5] Brantingham, P. J., \& Brantingham, P. L. (1981) Environmental Criminology. Beverly Hills, CA, USA: Sage Publications.
[6] Cohen, L., \& Felson, M. (1979) Social Change and Crime Rate Trends: A Routine Activity Approach. American Sociological Review, 44(4): 588-608.

[7] Brantingham, P. J., \& Brantingham, P. L. (1984) Patterns in Crime. New York, USA: MacMillan.

[8] Brantingham, P. J., \& Brantingham, P. L. (2008) Crime pattern theory. In: R. Wortley \& L. Mazerolle (Eds.), Environmental Criminology and Crime Analysis. Cullompton, Devon: Willan. pp. 78-93.

[9] Ashby, M. P. J. (2020) Initial evidence on the relationship between the coronavirus pandemic and crime in the United States. Crime Sci 9, 6. 
[10] Campedelli, G. M., Favarin, S., Aziani, A., \& Piquero, A. R. (2020) Disentangling community-level changes in crime trends during the COVID-19 pandemic in Chicago. COVID-19 Crime Research Seminar, UCL IDI Institute for Global City Policing, London.

[11] Piquero, A. R., Ridell, J. R., Bishopp, S. A., Narvey, C., Reid, J., et al.. (2020) Staying home, staying safe? A short-term analysis of COVID-19 on Dallas domestic violence. COVID-19 Crime Research Seminar, UCL IDI Institute for Global City Policing, London.

[12] Killias, M. (2006) The Opening and Closing of Breaches: A Theory on Crime Waves, Law Creation and Crime Prevention. European Journal of Criminology, 3(1): 11-31.

[13] Stickle, B., \& Felson, M. (2020) Crime Rates in a Pandemic: The Largest Criminological Experiment in History. American Journal of Criminal Justice, 45: 525-536.

[14] Mohler, G., Bertozzi, A. L., Carter, J., Short, M. B., Sledge, D., et al. (2020) Impact of social distancing during COVID-19 pandemic on crime in Los Angeles and Indianapolis, Journal of Criminal Justice, 68: 1-7.

[15] Sidebottom, A., \& Wortley, R. (2016) Environmental Criminology. In: A. R. Piquero (Ed.), The Handbook of Criminological Theory. John Wiley \& Sons, Inc. pp. 156-181.

[16] Tilley, T., \& Sidebottom, A. (2015) Routine Activities and Opportunity Theory. In: M. D. Krohn \& J. Lane (Eds.), The Handbook of Juvenile Delinquency and Juvenile Justice (pp. 331-348). John Wiley \& Sons, Inc

[17] Tillyer, M. S., \& Eck, J. E. (2011) Getting a handle on crime: A further extension of routine activities theory. Security Journal, 24: $179-193$

[18] Eck, J. E. (2003) Police problems: The complexity of problem theory, research and evaluation. In: J. Knutsson, (Ed.) ProblemOriented Policing: From Innovation to Mainstream (pp. 79-113). Monsey, NY, USA: Criminal Justice Press.

[19] Frailing, K., \& Harper, D. W. (2017) Toward a Criminology of Disaster: What We Know and What We Need to Find Out. New York, USA: Palgrave Macmillan.

[20] Rosenfeld, R. (2014) Crime and the Great Recession: Introduction to the Special Issue. Journal of Contemporary Criminal Justice 2014, 30(1): 4-6.

[21] Rosenfeld, R., \& Fornango, R. (2007) The impact of economic conditions on robbery and property crime: The role of consumer sentiment. Criminology: An Interdisciplinary Journal, 45(4): 735-769.
[22] Campaniello, N. (2013) Mega Events in Sports and Crime: Evidence From the 1990 Football World Cup. Journal of Sports Economics, 14(2): 148-170.

[23] Kurland, J., Johnson, S. D., \& Tilley, N. (2014) Offenses around stadiums: A natural experiment on crime attraction and generation. Journal of Research in Crime and Delinquency, 51(1): 5-28.

[24] Piquero, A. R., Piquero, N. L., \& Riddell, J. R. (2019) Do (sex) crimes increase during the United States Formula 1 grand prix? Journal of Experimental Criminology, 17: 87-108.

[25] Brantingham, P. J., Tita, G., Leap, J., \& Mohler, G. (2020) The Resilience of Gang-related Crime under COVID-19. COVID-19 Crime Research Seminar. UCL IDI Institute for Global City Policing, London.

[26] Aziani A., Campedelli G. M., \& Favarin, S. (2020) Exploring the effects and theoretical implications of SARS-CoV-2 containment policies: an empirical analysis of crime in Los Angeles. COVID-19 Crime Research Seminar, UCL IDI Institute for Global City Policing, London.

[27] Schnell, C., Braga, A. A., Piza, E. L. (2017) The Influence of Community Areas, Neighborhood Clusters, and Street Segments on the Spatial Variability of Violent Crime in Chicago. Journal of Quantitative Criminology, 33: 469-496.

[28] Halford, E., Dixon, A., Farrell, G., Malleson, N., \& Tilley, N. (2020) Crime and coronavirus: Social distancing, lockdown and the mobility elasticity of crime. Crime Science, 9(11): 1-12.

[29] Pietrawska, B., Aurand, S. K., \& Palmer, W. (2020) Covid-19 and crime: CAP's perspective on crime and loss in the age of Covid-19: Los Angeles crime. CAP Index, Issue 19.2. American Journal of Criminal Justice, 45: 525-536.

[30] Pietrawska, B., Aurand, S. K., \& Palmer, W. (2020) Covid-19 and crime: CAP's perspective on crime and loss in the age of Covid-19: Crime in Los Angeles and Chicago during Covid-19. CAP Index, Issue 19.3.

[31] Pietrawska, B., Aurand, S. K., \& Palmer, W. (2020) Covid-19 and crime: CAP's perspective on crime and loss in the age of Covid-19: Crime in Los Angeles and Chicago during Covid-19. CAP Index, Issue 19.4.

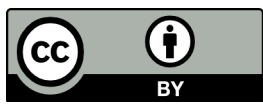
(C) 2021 by the Anna Murdoch, Caroline Byczynski. Submitted for possible open access publication under the terms and conditions of the Creative Commons Attribution (CC BY) license (http://creativecommons.org/licenses/by/4.0/). 